\title{
A Novel 3D-bioprinted Porous Nano Attapulgite Scaffolds with Good Performance for Bone Regeneration
}

This article was published in the following Dove Press journal: International Journal of Nanomedicine

\author{
Zehao Wang' \\ Aiping $\mathrm{Hui}^{2}$ \\ Hongbin Zhao ${ }^{3}$ \\ Xiaohan $\mathrm{Ye}^{4}$ \\ Chao Zhang \\ Aiqin Wang $\left(\mathbb{D}^{2, *}\right.$ \\ Changqing Zhang ${ }^{1} *$ \\ 'Department of Orthopedics, Shanghai \\ Sixth People's Hospital, Shanghai Jiao \\ Tong University, Shanghai 200233, \\ People's Republic of China; ${ }^{2}$ Key \\ Laboratory of Clay Mineral Applied \\ Research of Gansu Province, Center of \\ Eco-Material and Green Chemistry, \\ Lanzhou Institute of Chemical Physics, \\ Chinese Academy of Sciences, Lanzhou \\ 730000, People's Republic of China; \\ ${ }^{3}$ Changzhou No. 2 People's Hospital, \\ Changzhou 213000, People's Republic of \\ China; ${ }^{4}$ Beijing Tiantan Biological \\ Products Co., Ltd, Beijing 100000 , \\ People's Republic of China
}

*These authors contributed equally to this work

Correspondence: Aiqin Wang

Key Laboratory of Clay Mineral Applied Research of Gansu Province, Center of Eco-Material and Green Chemistry, Lanzhou Institute of Chemical Physics,

Chinese Academy of Sciences, Lanzhou

730000, People's Republic of China

Tel +86 93। 4968II8

Fax +86 931 8277088

Email aqwang@licp.cas.cn

Changqing Zhang

Department of Orthopedics, Shanghai

Sixth People's Hospital, Shanghai Jiao Tong

University, Shanghai 200233, People's

Republic of China

Tel +862 2l 6436918I

Fax +86 2I-6470I36I

Email zhangcq@sjtu.edu.cn
Background: Natural clay nanomaterials are an emerging class of biomaterial with great potential for tissue engineering and regenerative medicine applications, most notably for osteogenesis.

Materials and Methods: Herein, for the first time, novel tissue engineering scaffolds were prepared by 3D bioprinter using nontoxic and bioactive natural attapulgite (ATP) nanorods as starting materials, with polyvinyl alcohol as binder, and then sintered to obtain final scaffolds. The microscopic morphology and structure of ATP particles and scaffolds were observed by transmission electron microscope and scanning electron microscope. In vitro biocompatibility and osteogenesis with osteogenic precursor cell (hBMSCs) were assayed using MTT method, Live/Dead cell staining, alizarin red staining and RT-PCR. In vivo bone regeneration was evaluated with micro-CT and histology analysis in rat cranium defect model.

Results: We successfully printed a novel porous nano-ATP scaffold designed with inner channels with a dimension of $500 \mu \mathrm{m}$ and wall structures with a thickness of $330 \mu \mathrm{m}$. The porosity of current 3D-printed scaffolds ranges from $75 \%$ to $82 \%$ and the longitudinal compressive strength was up to $4.32 \pm 0.52 \mathrm{MPa}$. We found firstly that nano-ATP scaffolds with excellent biocompatibility for hBMSCscould upregulate the expression of osteogenesisrelated genes bmp2 and runx2 and calcium deposits in vitro. Interestingly, micro-CT and histology analysis revealed abundant newly formed bone was observed along the defect margin, even above and within the 3D bioprinted porous ATP scaffolds in a rat cranial defect model. Furthermore, histology analysis demonstrated that bone was formed directly following a process similar to membranous ossification without any intermediate cartilage formation and that many newly formed blood vessels are within the pores of 3D-printed scaffolds at four and eight weeks.

Conclusion: These results suggest that the 3D-printed porous nano-ATP scaffolds are promising candidates for bone tissue engineering by osteogenesis and angiogenesis.

Keywords: attapulgite, 3D-printing, porous scaffold, bone regeneration, nanomaterial, bone tissue engineering

\section{Introduction}

Bone defects remain a medical concern for orthopedists all over the world, bone graft has been performed and tissue engineering scaffolds have been utilized in order to achieve a good therapeutic effect. Bone graft is the most common therapeutic method applied in clinic, which can be categorized in autogenous and allogenic grafts. Autogenous bone graft is considered the "gold standard" 
when treating bone defects, however, significant drawbacks still exist, such as limited amount of materials that can be safely removed, long-term donor site morbidity, longer operation time and secondary traumatic stress. ${ }^{1,2}$ Thus, artificial bone substitutes became another optional solution for bone repair, and drew attention both of researchers and of clinicians. ${ }^{3-5}$ Currently hydroxyapatite, calcium sulfate, calcium phosphate, bioactive glasses, bioceramics and metal implants ${ }^{6-8}$ are widely used in clinic for bone defect repair, which are being developed as a promising strategy to enhance the biological performances of implants. ${ }^{9-13}$

Recently, the safety, biocompatibility, and potential bioactivity of nanoclays has drawn increasing attention to fabricate biomedical materials for bone tissue engineering. ${ }^{14,15}$ Nanoclays have been proposed as substrates and matrices to enhance stem and progenitor cell proliferation and differentiation. ${ }^{14}$ They are also considered an innovative platform for tissue regeneration and biomaterial design. ${ }^{16-18}$ The development of nanoclaybased inorganic-organic nanocomposites could generate renewed interest in the particular properties of nanoclays and their utility to fabricate novel functional biomaterials, with unique mechanical properties. ${ }^{19,20}$ Increasingly, clayprotein interactions, clay-polymer and clay-cell interactions are being tried for their potential in various therapeutic strategies, and these interactions and their combination can be applied in the design of biomaterials for tissue engineering and regenerative medicine. ${ }^{21-24}$

Attapulgite (ATP) is a naturally abundant nanoscale hydrated magnesium-rich clay mineral with a rod-like crystalline morphology and the structural formula of $\left(\mathrm{Al}_{2} \mathrm{Mg}_{2}\right) \mathrm{Si}_{8} \mathrm{O}_{2} \mathrm{O}(\mathrm{OH})_{2}\left(\mathrm{OH}_{2}\right)_{4} \cdot 4 \mathrm{H}_{2} \mathrm{O} .^{25,26}$ ATP also has a special crystal structure, stacking mode and nanometric dimension, which endows it with plentiful pores, higher aspect ratio, better ion-exchange capacity and affluent surface group, and enables it to be a candidate to fabricate various biological scaffolds. ${ }^{25,27-30}$ Furthermore, ATP possesses special nanoscale structure and microporeforming capability, which indicates that ATP is suitable for osteoblast ingrowth and neovascularization. ${ }^{31,32}$ ATP nanorods could form colloidal network structure with high viscosity due to the interaction among rods, and also form physical entanglement with other polymer chains to form stable blend. ${ }^{16,33}$ Inherent basic viscidity of ATP enables it to prepare a regular model or scaffold that displays certain compressive capacity. However, a lot of silanol groups on the surface of ATP leads to poor water resistance, which makes it hard to be directly used for bone repair. ${ }^{32,34}$ It is difficult for ATP to form applicable tissue engineering scaffold itself merely with inorganic compound, therefore, an appropriate amount of
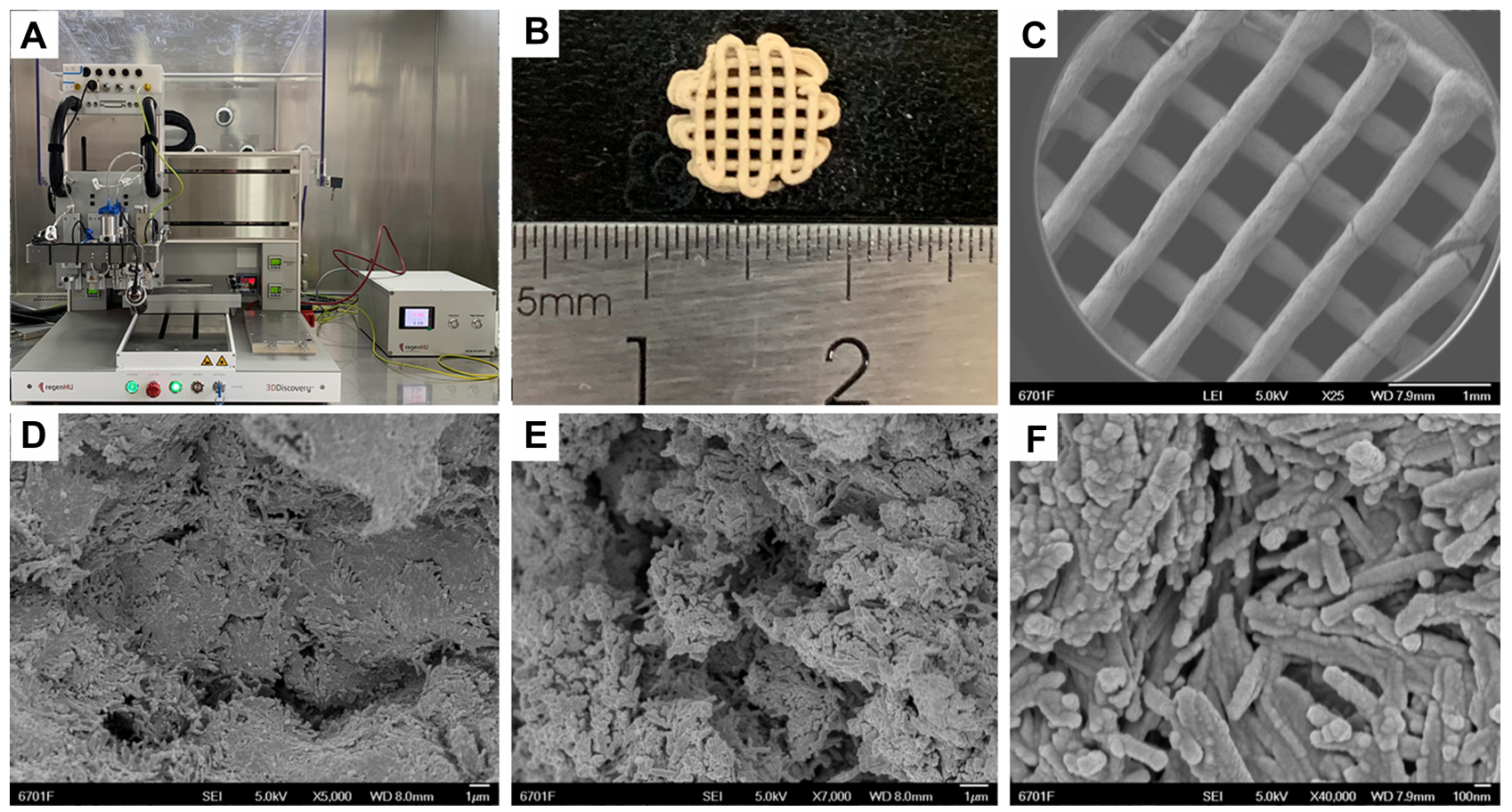

Figure I (A) Digital photograph of 3D printer, (B) digital photograph of green 3D-printed scaffold, SEM image of 3D-ATP scaffolds (C) $\times 25,($ D) $\times 5000,($ E) $\times 10,000$ and $(\mathbf{F}) \times 40,000$. 
binder plays a vital role for bonding ATP nanorods, and also generating certain pores in the model after calcination. $^{16}$

Three-dimensional (3D) printing, one of additive manufacturing techniques, is seen as a potential solution for bone biofabrication in recent years. It is a state-ofthe-art technology to fabricate biological constructs with hierarchical architecture similar to their native counterparts. $^{35}$ Furthermore, its inherent capability for reproducibility, accuracy and customization of scaffolds make 3D-printing a promising and innovative biofabrication strategy in bone tissue engineering. ${ }^{36-39}$ In addition, compared with conventional materials, nanoscale materials may be more efficient materials at stimulating new bone formation due to large specific surface area ratios and special topological conformation, which influence cellular differentiation and functions. ${ }^{36,38,40,41}$ By combining 3D-printing, nanotechnology, and materials science, bone tissue engineering exhibits enormous prospects for future development.

Herein, natural ATP was efficiently disaggregated by a high pressure homogenization technology to obtain highly dispersed ATP nanorods, which were employed as a starting material to fabricate novel bone repair scaffolds. ${ }^{33,42}$ A new type of tissue engineering scaffold was prepared by $3 \mathrm{D}$ bioprinter using nano-ATP with a polyvinyl alcohol (PVA) as a binder, and then sintered to obtain final scaffolds. After a final prototype of ATP scaffold was determined, its superior characters in mechanical strength, biocompatibility, biosafety, bone conductivity were studied both in vitro and in vivo.

\section{Materials and Methods Materials}

Natural attapulgite (ATP, Huangnishan Mine, PRC) was crushed and pretreated with $2 \mathrm{wt} \%$ aqueous sulfuric acid solution $\left(\mathrm{H}_{2} \mathrm{SO}_{4}\right.$, analytical grade, Xilong Scientific Co., Ltd, PRC) at a solid/liquid ratio of 1:10 to remove the associated carbonates, then the purified ATP powder was passed through a 200-mesh sieve. These powders were further disaggregated by combination of extrusion treatment and high-pressure homogenization technique. ${ }^{42}$

\section{Preparation of Nano-ATP Porous Scaffolds}

Firstly, 10wt\% PVA, type-1799, (Shanghai Macklin Biochemical Technology Co., Ltd, PRC) solution was prepared at $95 \sim 100^{\circ} \mathrm{C}$ for three hours in a water bath. Secondly, 50, 60, 70, 80, and $90 \mathrm{wt} \%$ of ATP powder was mixed with $10 \% \mathrm{wt}$ PVA solution respectively to make the mixtures containing different concentration of ATP powder, each of which then was molded into scaffolds of $7 \mathrm{~mm}$ diameter and $3 \mathrm{~mm}$ thickness at a pressure of 10 bar to explore the optimal ATP content. Then the mixture with the optimal solid content of ATP powder was loaded in 3D Discovery bioprinter (Figure 1A) (RegenHu Ltd, Switzerland), and 3D scaffolds were printed with a DD135-N spray nozzle of $\Phi 0.33 \mathrm{~mm}$, at the speed of $2 \mathrm{~mm} / \mathrm{s}$ and under pressure of $0.4 \mathrm{MPa}$. The dimension of the obtained 3D nano-ATP scaffolds was $7 \mathrm{~mm}$ (diameter, $\Phi) \times 3 \mathrm{~mm}$ (height, h) in order to fit the size of defect for animal model. The scaffolds were designed to be printed into a square-perforated structure with an approximate $0.5 \mathrm{~mm}$ in size for each square. In addition, the mixture was also used to prepare ATP scaffolds by squash technique. Next, the intermediate scaffolds by both 3D-printing and squash techniques were dehydrated respectively by ethanol gradient $(50,60,70,80,90,95$, and $100 \%$ ethanol solution, $30 \mathrm{~min}$ for each gradient), the scaffolds were placed overnight in an oven at $37^{\circ} \mathrm{C}$ and sintered at $500^{\circ} \mathrm{C}$ for two hours in an open atmospheric furnace. Finally, the scaffolds were soaked in PBS for $24 \mathrm{~h}$, oven dried at $60^{\circ} \mathrm{C}$ for one hour and sterilized for further use.

\section{Characterizations}

The surface morphology was observed on a field emission scanning electron microscope (FESEM, JSM-6701F, JEOL, Ltd, Japan) after the samples were fixed on copper stubs and coated with a gold film. TEM images were taken using a high-resolution transmission electron microscope (Tecnai G2 F20, FEI, USA) after the sample was dispersed in anhydrous ethanol by sonication and dropped onto a micro grid. XRD patterns were collected using an X'Pert PRO diffractometer (PANnalytical, Netherlands) equipped with a $\mathrm{Cu}-\mathrm{K} \alpha$ radiation source $(40 \mathrm{kV}, 40 \mathrm{~mA})$ in a fixed time mode, with a step interval of about $0.167^{\circ}$. Two milligrams of ATP powder was mixed with $200 \mathrm{mg}$ of dried potassium bromide, then compressed into pellets which were loaded on a Nicolet NEXUS spectrometer to obtain Fourier Transform infrared (FTIR) spectra with scanning range of $4000-400 \mathrm{~cm}^{-1}$.

ATP scaffolds with different ATP additions were separately tested for their compressive strength with a New SANS universal material testing system (CMT4304, Yinfei Co., Ltd, PRC). For each test, a crosshead speed 
of $2 \mathrm{~mm}$ per min and an initial gauge length of $8 \mathrm{~mm}$ were operated while stress-strain curve was monitored, and the test was terminated as the stress value starts to decline or the linear deformation reaches $40 \%$. The ATP scaffolds were tested six times, and the average was recorded. The porosity value of the 3D-printed scaffolds was measured with the liquid displacement method.

\section{In vitro Biocompatibility and Osteogenesis Evaluation Cells Culture and Reagents}

African green monkey kidney cells (Vero cells) were obtained from National Institutes for Food and Drug Control (NIFDC, P127, 3115CNCB00351), then cultured at $37^{\circ} \mathrm{C}$ in a humidified atmosphere of $5 \% \mathrm{CO}_{2}$ with the growth medium (low glucose DMEM, (Hyclone, USA) with 10\% FBS (Gibco, USA), 1\% penicillin-streptomycin solution (Gibco)) that was changed every three days. Human bone marrow mesenchymal stem cells (hBMSCs, Cyagen Biosciences, USA) were cultured at $37^{\circ} \mathrm{C}$ in a humidified atmosphere of $5 \% \mathrm{CO}_{2}$ with the growth medium DMEM with $10 \% \mathrm{FBS}, 1 \%$ penicillin-streptomycin solution and the medium was changed every other day, and all experiments were performed with cells within five passages.

According to the International Organization for Standardization (ISO 10,993-12), briefly, the extracts with sterile ATP powder or 3D ATP scaffolds were prepared respectively at concentration of $100 \mathrm{mg} / \mathrm{mL}$ into serum-free DMEM. After incubation at $37^{\circ} \mathrm{C}$ for $24 \mathrm{~h}$, the mixture was centrifuged and the supernatant was collected. Then, the extract was filtrated with $0.2 \mu \mathrm{m}$ filter membranes and stocked.

\section{MTT Assay}

3-(4,5-dimethylthiazol-2-yl)-2,5-diphenyl tetrazolium bromide (MTT) colorimetric assay was employed to evaluate the biocompatibility of sintered ATP powder with Vero cells and ATP scaffolds with hBMSCs. In short, Vero cells were seeded in 96-well plates at $5 \times 10^{3}$ cells/well for $24 \mathrm{~h}$, then were cultured with extracts of various ATP powder concentrations $(100,50,25,12.5,6.25$, and
$3.125 \mathrm{mg} / \mathrm{mL}$ ). hBMSC were seeded in 96-well plates at $5 \times 10^{3}$ cells/well for $24 \mathrm{~h}$, then were cultured with extracts of 3D ATP scaffolds of $100 \mathrm{mg} / \mathrm{mL}$ described above. After cultured for one, four, and seven days, the cells at each time point were dyed with supplement MTT (Jiancheng, Nanjing, PRC) according to instructions (aliquots of 100 $\mu \mathrm{L}$ were pipetted into 96-well plates). Finally, 96-well plates were measured at $570 \mathrm{~nm}$ by ELX Ultra Microplate Reader (BioTek, USA). All experiments were performed in triplicate.

\section{Live/Dead Cells Staining}

To investigate the cells' proliferation and death, a Live/ Dead Cell Staining Kit (Abnova, Taiwan, KA0901) was used for the discrimination between live and dead cells. Briefly, different cells were seeded in six-well plates at $2.0 \times 10^{5}$ cells $/ \mathrm{cm}^{2}$, after being cultured for $24 \mathrm{~h}$, the medium of six-well plates were substituted with ATP powder or scaffold extracts at a concentration of $100 \mathrm{mg} / \mathrm{mL}$ respectively. After culturing for one, four, and seven days, the cells at each time point were dyed with LiveDye (a green fluorescent dye for live cells, $\mathrm{Ex} / \mathrm{Em}=488$ / $518 \mathrm{~nm}$ ) and propidium iodide (PI, a red fluorescent dye, $\mathrm{Ex} / \mathrm{Em}=488 / 615)$. After incubation for $15 \mathrm{~min}$ at $37^{\circ} \mathrm{C}$, stained live and dead cells in six-well plates can be visualized by fluorescence microscopy using a band-pass filter.

Alizarin Red (AR) Staining and Quantitative Analysis hBMSCs were seeded in six-well plates at $3.0 \times 10^{4}$ cells $/ \mathrm{cm}^{2}$ and cultured in ordinary medium for $24 \mathrm{~h}$ and then medium was switched with nano-ATP scaffolds extracts $(100 \mathrm{mg} /$ $\mathrm{mL}$ ), and supplemented with the culture medium containing $10 \%$ FBS, $1 \%$ penicillin-streptomycin solution, $10 \mathrm{mM} \beta-$ glycerophosphate (Sigma), $0.1 \mu \mathrm{M}$ dexamethasone (Sigma), and $50 \mu \mathrm{M}$ ascorbate 2-phosphate (Sigma). At the same time a blank control was prepared without extracts. The medium was replaced every three days for two weeks. Calcium deposition (mineralization) was assessed by alizarin red staining. After culturing for 14 days, cells were fixed with $4 \%$ paraformaldehyde for $15 \mathrm{~min}$ at $37^{\circ} \mathrm{C}$ prior to being stained with a $1 \%(\mathrm{w} / \mathrm{v})$ alizarin red solution for $45 \mathrm{~min}$. Then the samples were washed with PBS to remove

Table I Primer Design

\begin{tabular}{|l|l|l|}
\hline Gene & Forward Primer & Reverse Primer \\
\hline runx 2 & GAAATGCTGGAGTGATGTGG & GTTTGGTAAGGCTGGTTGGT \\
bmp2 & GCCTTGCCCGACACTGAGAC & CATTGAAAGAGCGTCCACAT \\
18 srRNA & GTAACCCGTTGAACCCCATT & CCATCCAATCGGTAGTAGCG \\
\hline
\end{tabular}


nonspecific staining and directly observed by optical microscopy. For the quantitative analysis, $10 \%$ acetic acid was added and neutralized with $10 \%$ ammonium hydroxide. Then, $100 \mu \mathrm{L}$ of the supernatant was added to 96 -well plates and measured at $405 \mathrm{~nm}$ with a plate reader.

\section{Gene Expression by Real-time RT-PCR}

The hBMSCs were seeded in six 6 -well plates at $2.0 \times 10^{5}$ cells/ well, after culturing for $24 \mathrm{~h}$, the medium of six-well plates was substituted with extracts at a concentration of $100 \mathrm{mg} / \mathrm{mL}$ described above. The cells were harvested after culture of 7 sevendays using TRNzol (Qiagen, Germany) to extract the total RNA. After extraction, samples were centrifuged at $12,000 \mathrm{~g}$ for $15 \mathrm{~min}$ at $4^{\circ} \mathrm{C}$. Then, RNA was reverse transcribed into complementary DNA for $20 \mathrm{~min}$ at $46^{\circ} \mathrm{C}$, then for one minute at $95^{\circ} \mathrm{C}$ and combined with the RT-PCR mixture (Bio-Rad, California, USA). The qRT-PCR assay was conducted within the mixture using SYBR Green PCR Master Mix (Roche Diagnostics, Basel, Switzerland). In this study,
$18 \operatorname{sr} N A$ was selected as the housekeeping gene used to standardize mRNA levels. The primers used in this study were listed in Table 1.

\section{In vivo Osteogenesis Evaluation \\ Animal Experiment}

All experimental protocols (Laboratory animal-Guideline for ethical review of animal welfare, GB/T 35,892-2018, General Administration of Quality Supervision, Inspection and Quarantine of the PRC) were approved by the Animal Research Committee of Shanghai Jiaotong University School of Medicine. Thirty 16-week-old male Sprague Dawley rats weighing 250-300 g were randomly divided into three groups (10 for each group) for in vivo bone regeneration evaluation. Group I served as blank controls and just for bone defect model, which did not receive any therapy; Group II (s-ATP) were implanted with nano-ATP scaffold prepared with squash technique at the bone defect; Group III (3D-ATP) were implanted with nano-ATP scaffold prepared with 3D
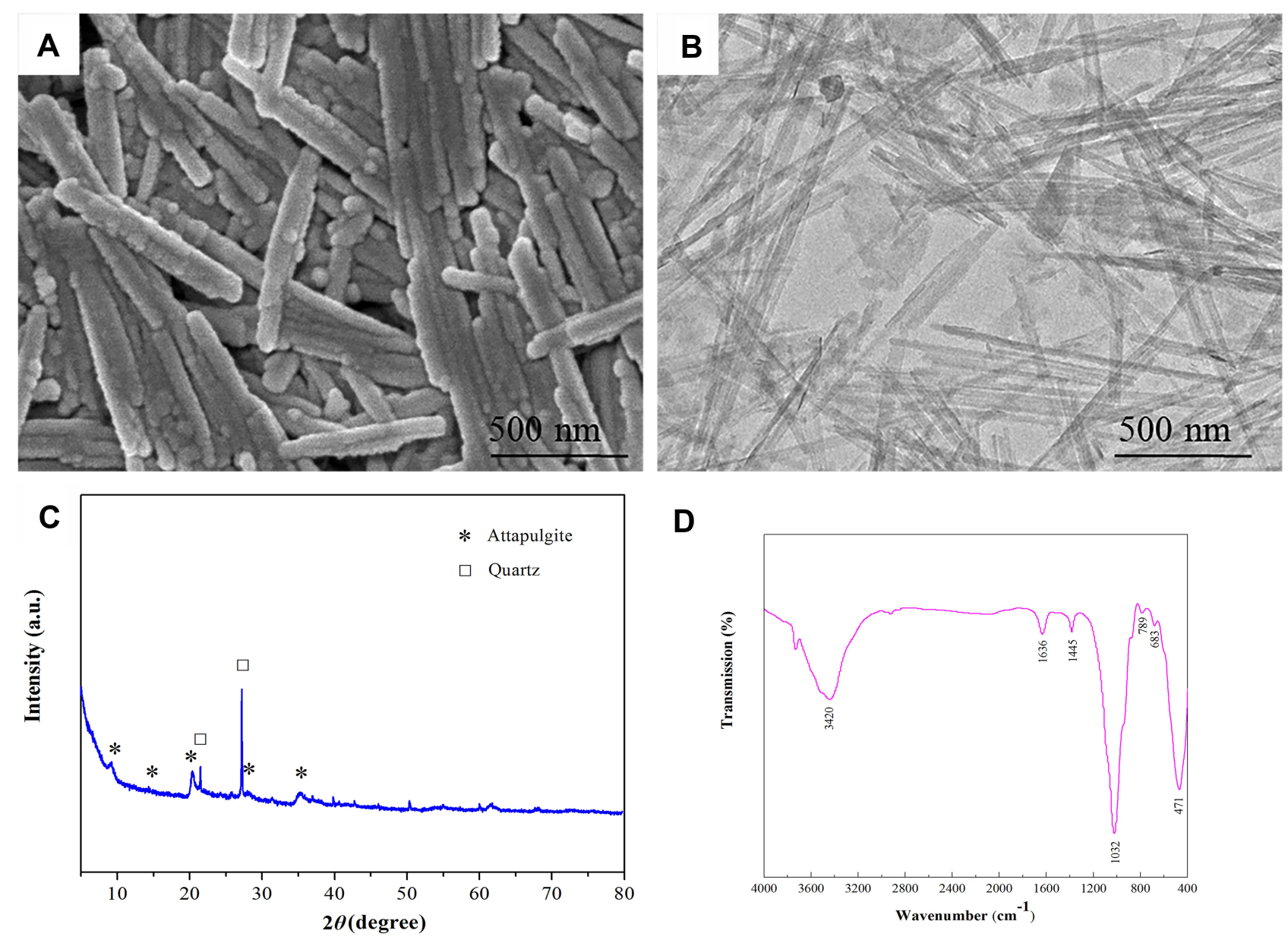

Figure 2 Microscopic morphology and phase analysis of nano-ATP powders. (A) SEM image and (B) TEM image of nano-ATP rods. (C) XRD patterns (*For characteristic peaks of ATP, $\square$ For characteristic peaks of quartz), (D) FTIR spectra. 
bioprinting technique. The surgery was operated under general anesthesia by intraperitoneal injection of 3\% chloral hydrate $(1 \mathrm{~mL} / 100 \mathrm{~g})$. Briefly, an incision of approximately $1.8 \mathrm{~cm}$ was made over the scalp with a scalpel to expose the calvarium. Subsequently, underlying bone was exposed by carefully splitting periosteum. A 5-mm-diameter cranial defect was created on the bilateral sides of the midline using a trephine drill under continuous sterile saline irrigation. Scaffolds were then implanted into the defects, and the soft tissue and skin were successively sutured over the implant. No complications were reported after operation. After being housed for four and eight weeks, the animals were sacrificed, and craniums were aseptically retrieved without soft tissues. Then, these samples were fixed in $10 \%$ neutral buffered formalin for seven days and saved for further use.

\section{Microcomputed Tomography (Micro-CT) and Histological Analysis}

Samples described above were scanned using a $\mu \mathrm{CT} 50$ micro-CT scanner (SCANCO Medical AG, Switzerland) with a $10 \mu \mathrm{m}$ isotopic resolution at $70 \mathrm{kV}$. Threedimensional models of the samples were also constructed using $\mu \mathrm{CT}$ Evaluation and Visualizer Programs (SCANCO Medical AG). The percentage of newly formed bone volume within each defect was calculated. The extent of bony bridging and union within the defect was scored according to the grading scale. ${ }^{44}$ When micro-CT scan finished, these samples were decalcified with 15\% ethylenediaminetetraacetic acid for one month. After dehydration by ethanol gradient, samples were embedded in paraffin and sliced into sections for histological analysis (H\&E staining). Finally, the slices were mounted for examination by light microscopy. Density of neo-vessels within the macro pores in 3D ATP scaffolds was calculated.

\section{A}

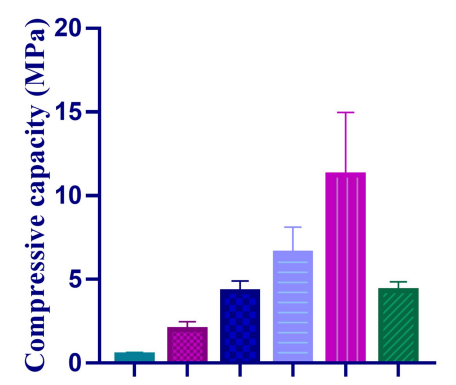

\section{Statistical Analysis}

The data are expressed as the mean \pm SD. Statistical analysis was carried out using one-way or two-way analysis of variance (ANOVA) followed by a post hoc method as recommended loaded in the GraphPad (v8.3.0.538, GraphPad Software, USA) to test difference between various groups or time points. $P$ value $<0.05$ was considered to indicate a statistically significant difference.

\section{Results}

\section{Characterization of ATP Scaffolds}

The characterization of the ATP particles with different technologies were shown in Figure 2, by SEM it was observed the ATP nanorods with length of $0.5 \sim 1.0 \mu \mathrm{m}$ and diameter of approximately $30 \mathrm{~nm}$ (Figure 2A and B); as for the IR spectrum, the characteristic bands at $3440 \mathrm{~cm}^{-1}$ and $1630 \mathrm{~cm}^{-1}$ were corresponding to free $-\mathrm{OH}$ and $\mathrm{H}-\mathrm{O}-\mathrm{H}$ groups, $1032 \mathrm{~cm}^{-1}$ and $471 \mathrm{~cm}^{-1}$ were ascribed to, $\mathrm{Si}-\mathrm{O}$ stretching vibrations and $\mathrm{Mg}-\mathrm{O}$ groups respectively (Figure 2D). The characteristic reflections of ATP at $2 \theta$ values of $8.4^{\circ}$ (110 plane, $d=1.05 \mathrm{~nm}), 14.1^{\circ}$ (200 plane), $19.6^{\circ}$ (040 plane), $27.7^{\circ}$ (400 plane) and 34.4 (102 plane) were found in the XRD pattern (Figure 2D). The reflection at $2 \theta$ of $26.6^{\circ}$ was related to the quartz (Figure 2D). All characteristic peaks of the XRD and IR spectra of ATP scaffolds observed in present study were consistent with those in previously reported studies. ${ }^{33,42}$

Green porous scaffolds (Figure 1B) were successfully printed with the overall dimensions similar to the corresponding dimensions of the 3D computer models. A slight shrinkage of the wet species was observed after dehydration by ethanol gradient. No obvious sintering shrinkage was observed. The final scaffolds (Figure 1C)

\section{B}

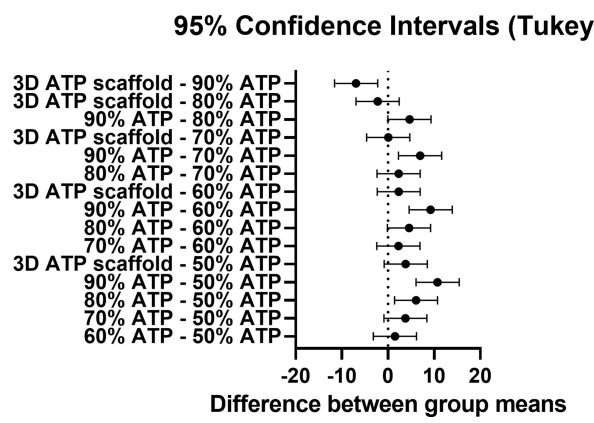

Figure 3 (A) Compressive strength of ATP scaffolds with various amounts of ATP and 3D-ATP scaffold, (B) multicomparisons following one-way analysis of variance (ANOVA) using a post hoc Tukey method as recommended in the GraphPad software to test differences between various groups. $P$ value $<0.05$ was considered to indicate a statistically significant difference. The $95 \% \mathrm{Cl}$ reveals that the result is statistically significant when " 0 " is not included in the interval, and vice versa. 
demonstrated the good preservation of the shape as well as the inner structure. It is interesting to note that the staggered arrangement of ATP nanorods in the scaffolds, and carbonized PVA molecules give rise to vacancies in the scaffolds (Figure 1D). It was seen that the longitudinal section possesses a certain microporous structure (Figure 1D and E). The micropore size within wall structure of the scaffold in the present study was in the range of 20-50 $\mu \mathrm{m}$. In addition, the ATP nanorods remain intact after high-temperature sintering treatment, the staggered arrangement of ATP nanorods present a pattern to form large gaps (Figure $1 \mathrm{~F}$ ).

Figure 3 displays the effect of ATP contents on the compressive capacity of ATP scaffolds. The compressive capacities increased continually along with the increase of ATP content. The compressive strength of ATP scaffolds are shown to be $0.49 \pm 0.35 \mathrm{MPa}, 2.33 \pm 1.04 \mathrm{MPa}, 4.17 \pm 1.26 \mathrm{MPa}, 5.57 \pm 2.43$ $\mathrm{MPa}, 11.23 \pm 3.74 \mathrm{MPa}$ and $4.32 \pm 0.52 \mathrm{MPa}$ for the ATP scaffolds by squash technique with $50,60,70,80$, and $90 \mathrm{wt} \%$ of ATP and 3D-printing of $90 \mathrm{wt} \%$ ATP, respectively. In particular, the compressive capacity increased by 21.92 -folds with the ATP contents increased from $50 \%$ to $90 \%$. Ninety percent of ATP content was chosen for preparing 3D-printed scaffolds, which still showed good performance of compressive capacity with interconnected channels within the scaffolds.

\section{In vitro Biocompatibility and Osteogenesis Assay}

As shown in Figure 4, Vero cells proliferation assay and Live/Dead staining reveal that ATP powders possess ideal biocompatibility. The results of MTT test demonstrated that at each of three time points, there is no significant difference in the OD values among all groups respectively (Figure 4B). A significant difference of proliferation was observed in all groups between days one and four (Figure 4C), between days one and seven (Figure 4C). In groups with relatively higher concentration of extracts (more than $25 \mathrm{mg} / \mathrm{mL}$ ), a significant difference was observed between days four and seven with a slight difference in groups with relatively lower concentration of extracts (less than $25 \mathrm{mg} / \mathrm{mL}$ ). Meanwhile, the result of Live/Dead staining also demonstrated that Vero cells cultured in $100 \mathrm{mg} /$ $\mathrm{mL}$ extract and control groups were of similar proliferation $(P<0.05)$. The live cells utilized Live-Dye and stained green, while dead cells stained by PI appeared red (Figures 4D and 5D), the extract and the control groups show similar cell growth trend. Similar results of MTT assay and Live/Dead staining of hBMSCs were seen between the two groups (Figure 5). However, significant increase of hBMSCs was observed in nano-ATP and control groups as culture time increased (Figure 5C). The
A

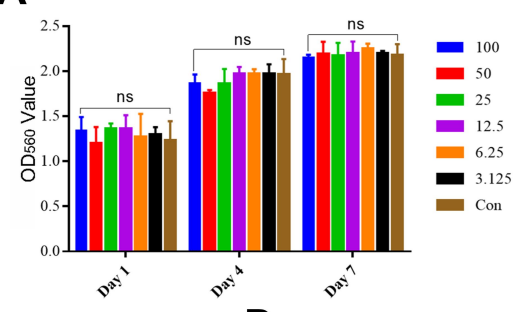

D
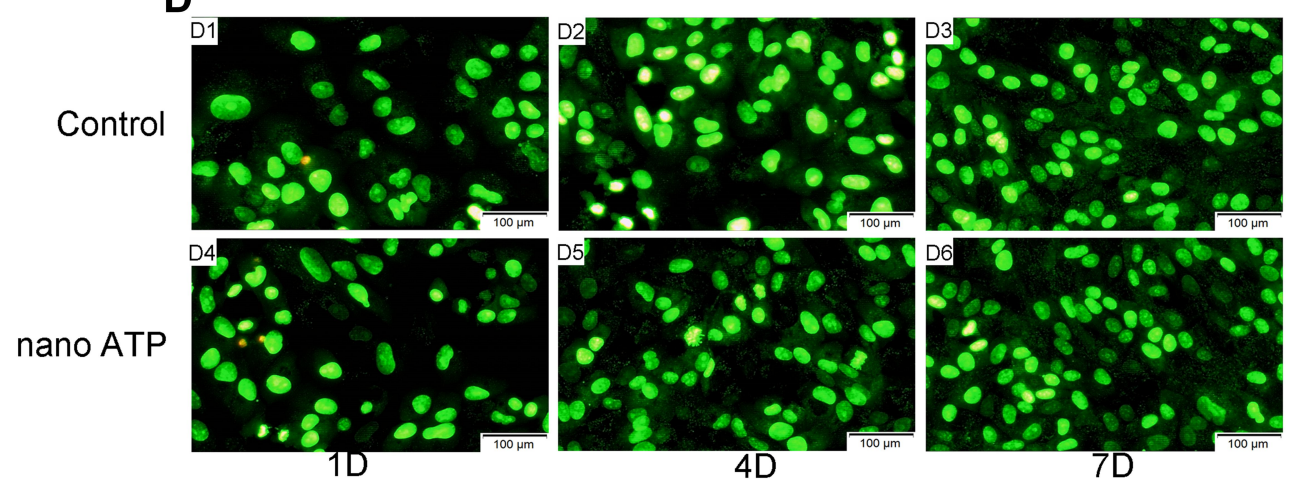

B

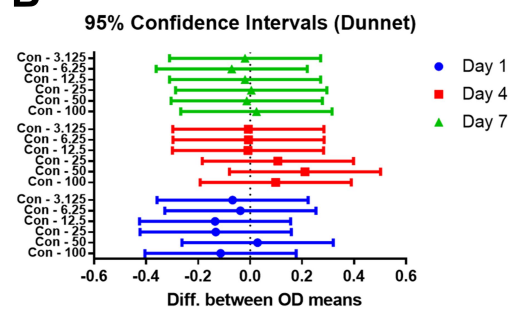

C

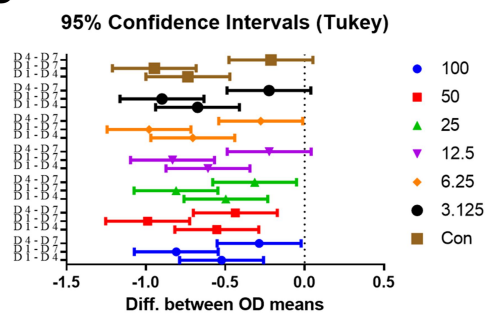

Figure 4 (A) MTT assay of vero cells cultured with various extracts from nano 3D-ATP scaffolds at three time points ("ns" represents no statistical difference). (B) Multicomparisons following two-way analysis of variance (ANOVA) using a post hoc Dunnet method as recommended in the GraphPad software to test differences between various ATP groups and control. (C) Multicomparisons following two-way analysis of variance (ANOVA) using a post hoc Tukey method as recommended to test differences between various time points within the given group. The $95 \% \mathrm{Cl}$ reveals that the result is statistically significant when " 0 " is not included in the interval, and vice versa. (DI for day I, D4 for day 4, D7 for day 7), (D) Live/Dead staining of Vero cells between extract and control group at three time points of days one, four, and seven. 
A

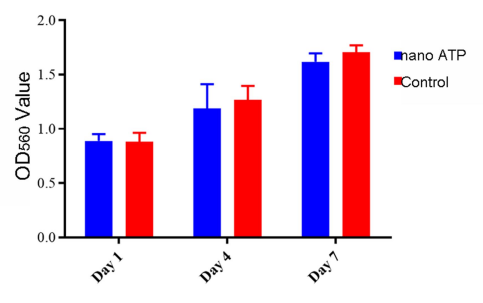

D

Control

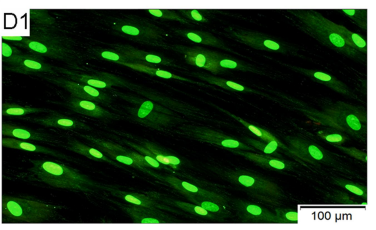

nano ATP

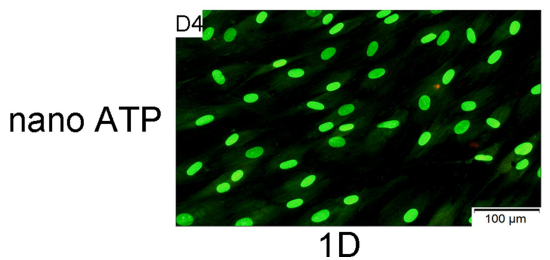

B

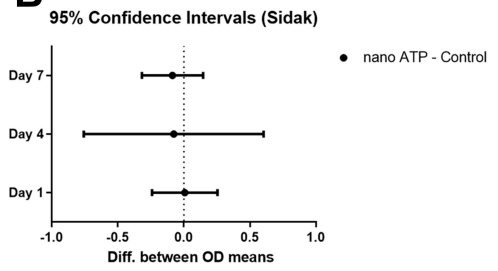

C

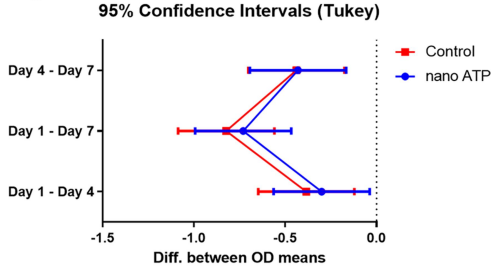

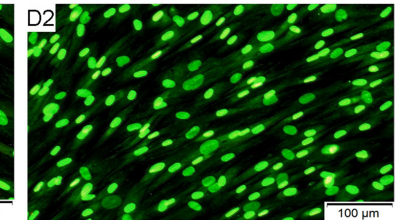
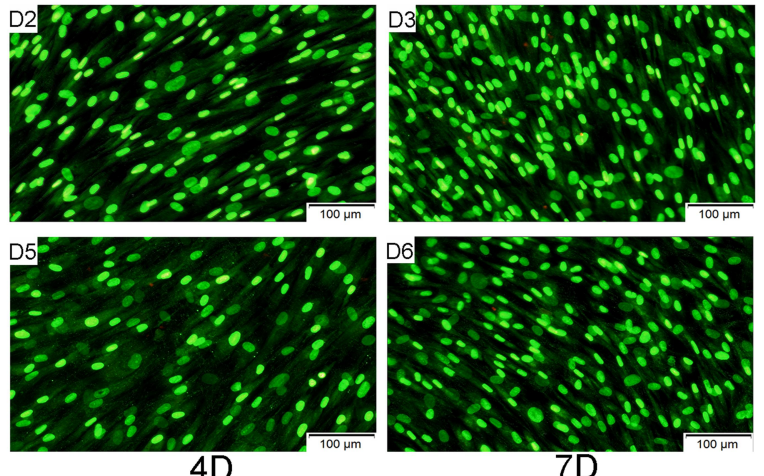

Figure 5 (A) MTT assay of hBMSCs cultured with extract from nano 3D-ATP scaffolds at three time points. (B) Multicomparisons following two-way analysis of variance (ANOVA) using a post hoc Sidak method as recommended to test differences between various groups. (C) Multicomparisons following two-way analysis of variance (ANOVA) using a post hoc Tukey method as recommended to test differences between various time points within the given group. The $95 \% \mathrm{Cl}$ reveals that the result is statistically significant when " 0 " is not included in the interval, and vice versa. (D) Live/Dead staining of hBMSCs between extract (I00 mg/mL) and control group at three time points of days one, four and seven.

Blank

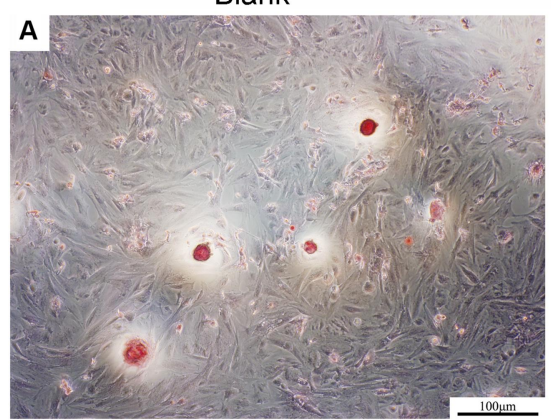

nano ATP

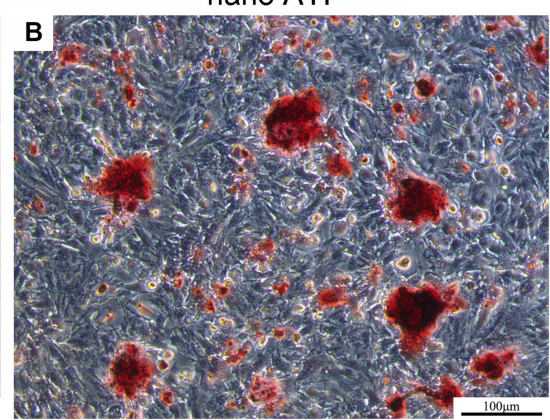

C

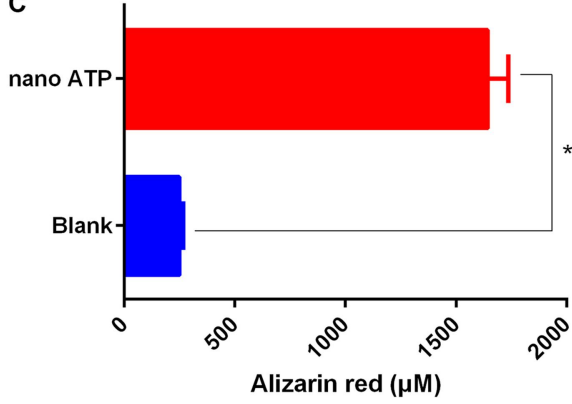

Figure 6 Alizarin red (AR) staining and quantitative analysis. (A and B) AR staining of BMSCs cultured with osteogenic medium for I4 days. (C) Quantitative analysis of the AR staining. $* P<0.05$.
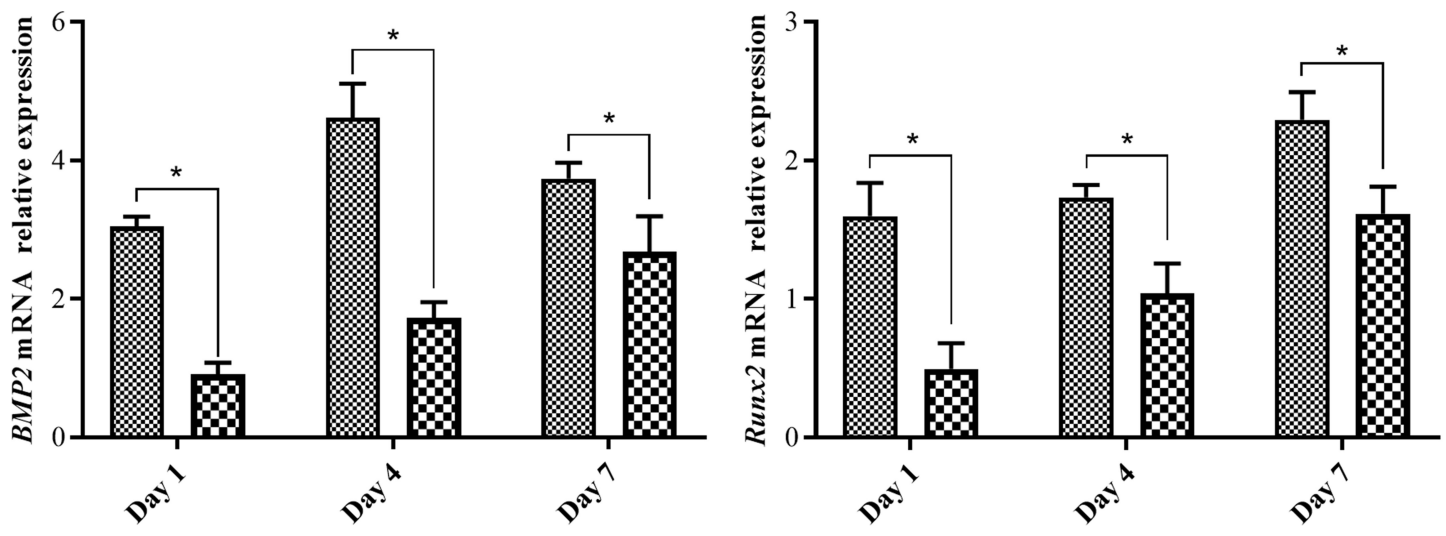

$\otimes$ ATP

Blank

Figure 7 mRNA expression of BMP2 and Runx2 by real-time RT-PCR. $* P<0.05$. 
morphology of Vero cells in the nano-ATP group was similar to that in the control group at every time point (Figures 4D and 5D).

The calcium nodules generated by hBMSCs were observed by alizarin red staining, and the amount of calcium deposition was quantitatively analyzed. As shown in Figure 6, when hBMSCs were cultured for 14 days, the stained calcium deposits appeared as red spots obviously in both groups. Compared with control group, the nano-ATP group demonstrated a greater number of red spots and the red calcium nodules were much bigger in nano-ATP group.
A quantitative analysis of the mineralized products based on the dissolved dyes is displayed in Figure 6C. It was observed that hBMSCs cultured in the nano-ATP group showed a significant increase in the amount of calcium deposition $(1643 \pm 92.92 \mu \mathrm{m})$ compared with that of cells cultured in control group $(250.3 \pm 16.50 \mu \mathrm{m})(P<0.001)$.

To further investigate the osteogenic differentiation of hBMSCs induced by nano-ATP, we examined the expression levels of runx 2 and bmp 2 by real-time PCR (Figure 7). runx2, an early marker of osteoblast differentiation, is essential for the commitment of

\section{Surface}
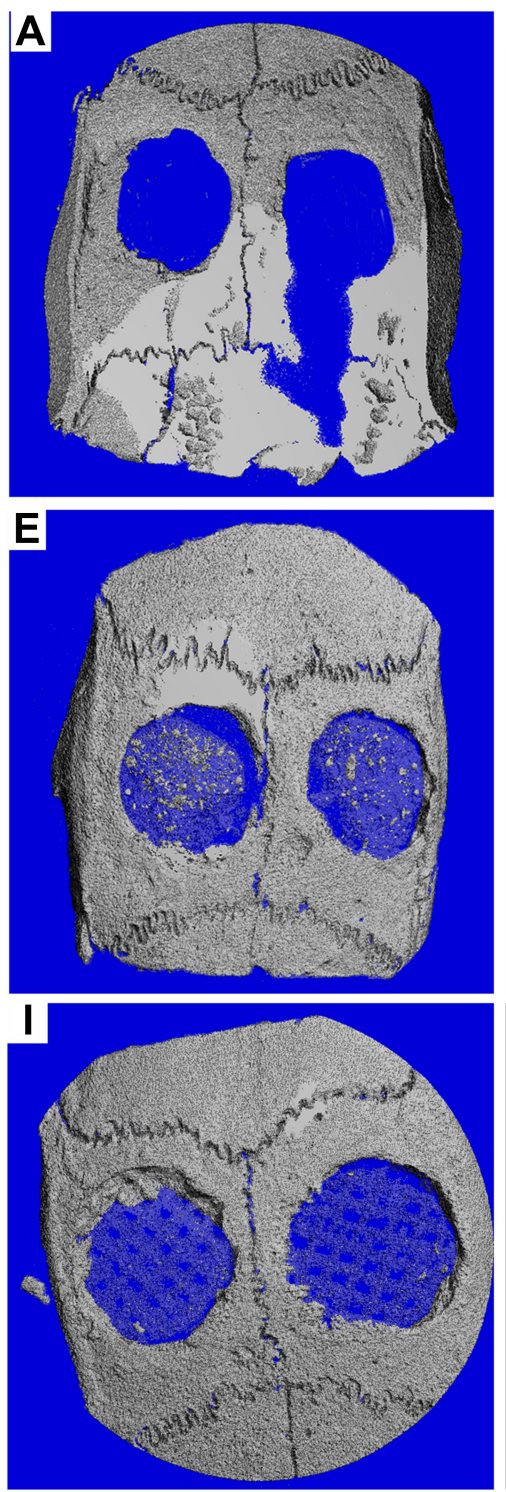

MIP
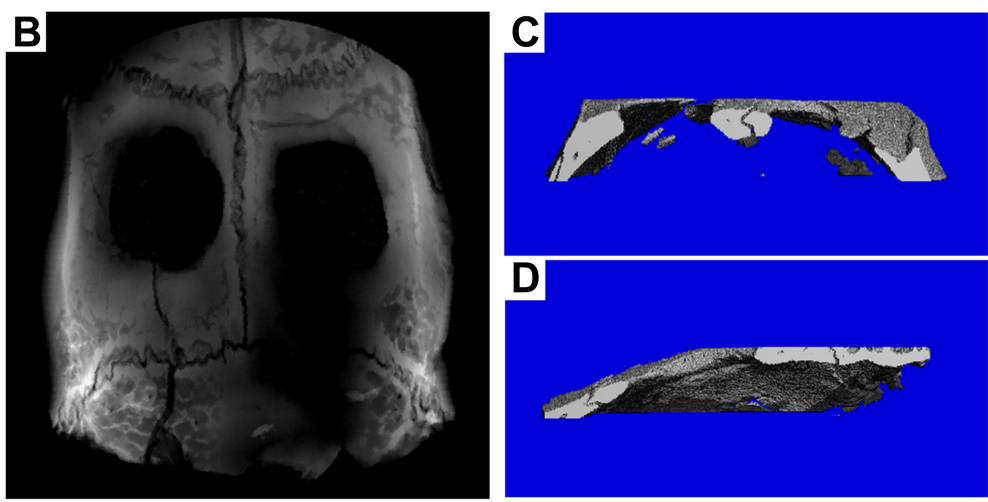

Coronal

Blank

Sagittal
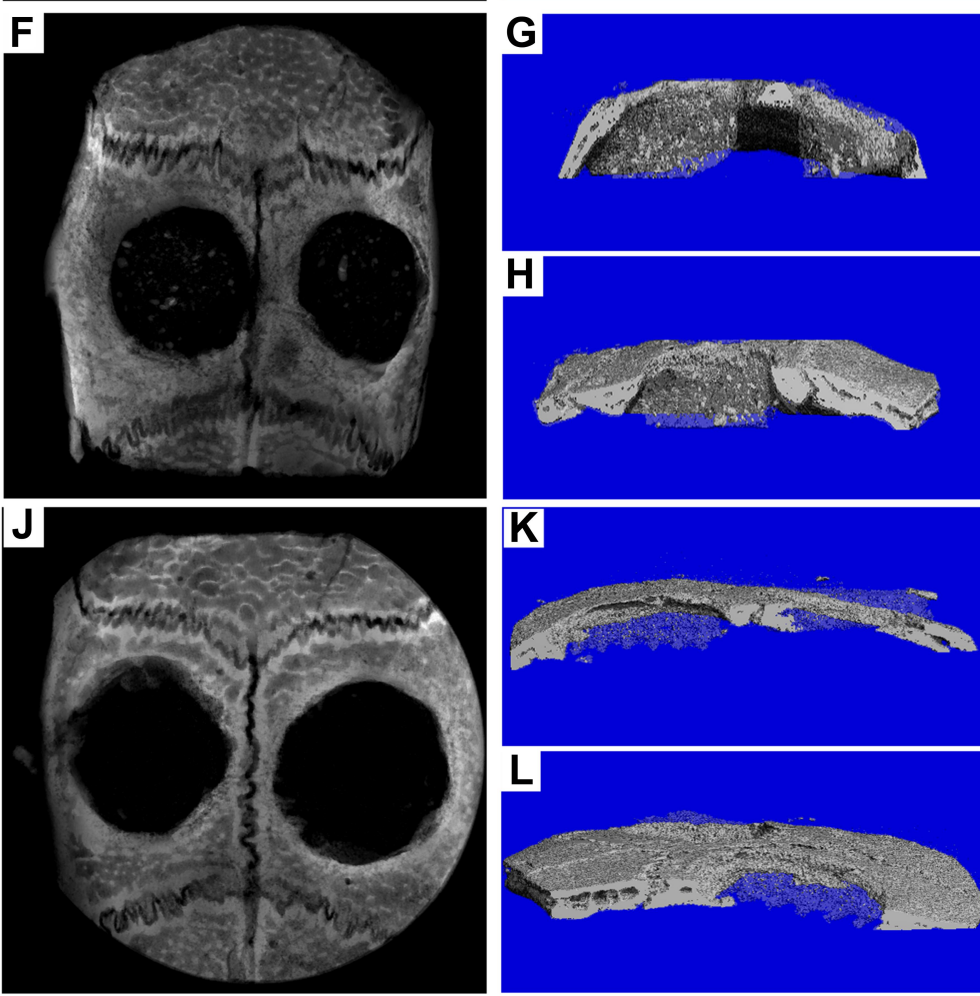

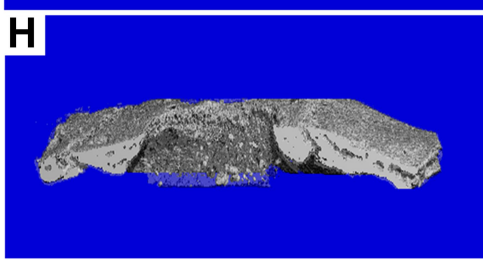

s-ATP

Sagittal

Coronal

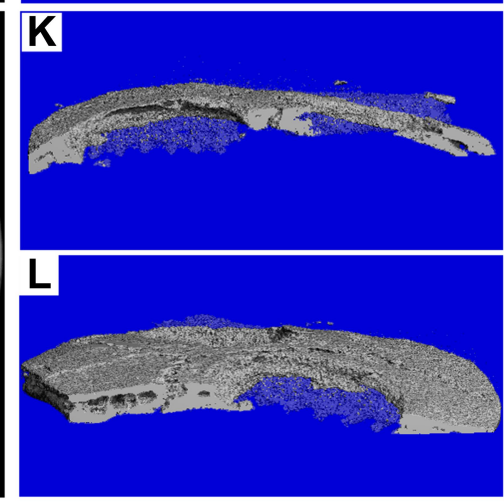

Coronal

3D-ATP

Sagittal

Figure 8 Micro-CT images of the bone defects in rats after implantation of ATP scaffolds for four weeks. (A-D) Blank group, (E-H) squashed ATP scaffold group and (I-L) 3D-ATP scaffold group. MIP is short for maximum intensity projection. Surface refers to outside appearance of cranium. Coronal plane is vertical to sagittal suture of rat's cranium. Sagittal plane is parallel to sagittal suture of rat's cranium. 
multipotent mesenchymal cells into the osteoblastic lineage. There was significant difference in runx 2 expression between the two groups of control and nano-ATP at different time points $(P<0.05)$, and the difference was more obvious as the culturing time increased. The highest levels observed on day seven. Meanwhile, bone matrix proteins (such as bmp2), one target gene of runx2, possess potent osteoinductive capacity for bone formation. bmp 2 was significantly upregulated in cells cultured with nano-ATP compared to the control group at different time points $(P<0.05)$.
But the highest levels of bmp2 expression were observed on day four.

\section{In vivo Osteogenesis Evaluation Micro-CT Analysis}

In rats' cranial defects model study, micro-CT was taken to analyze new bone formation in the defect regions. At four and eight weeks postimplantation, the 3D images of micro-CT reconstruction indicated that new bone formation within the bone defect regions in the 3D-ATP group were significantly more than that in s-ATP and blank
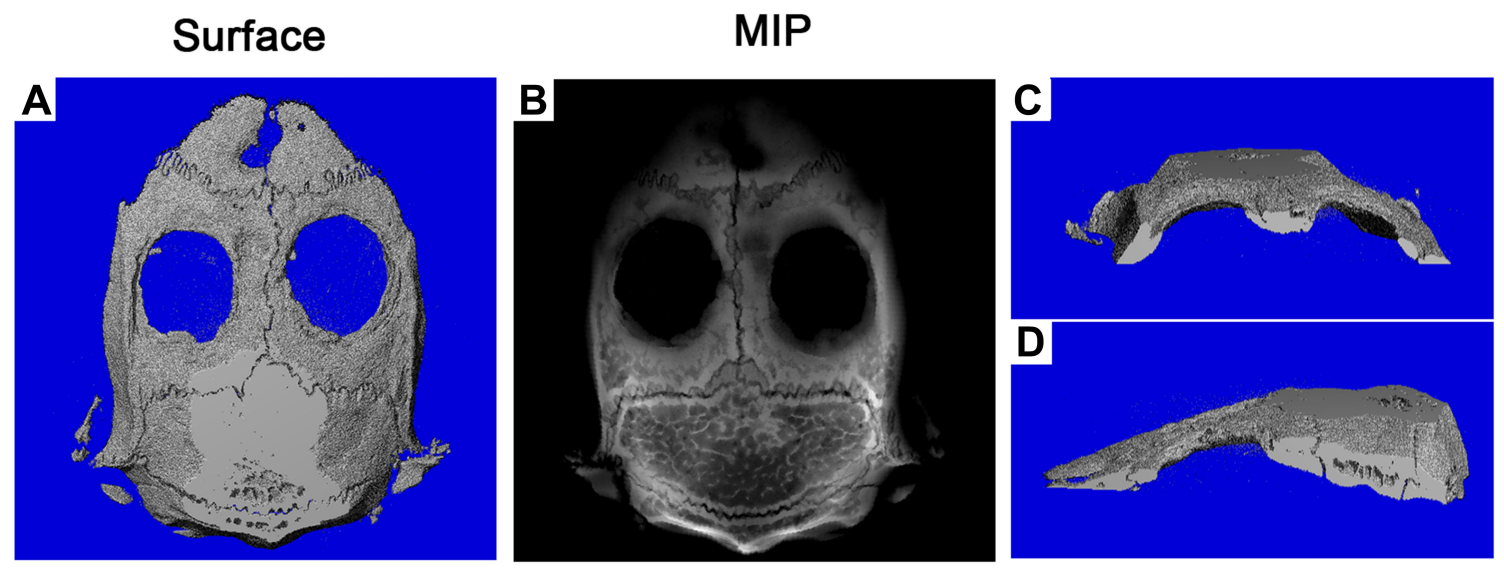

Coronal
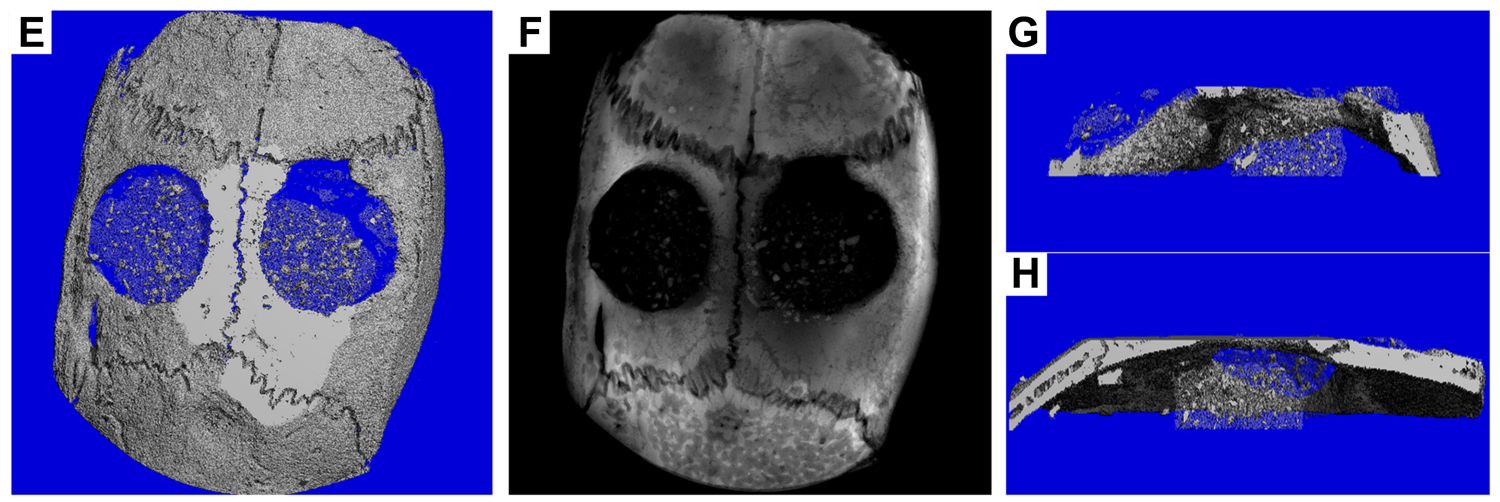

Blank

Sagittal
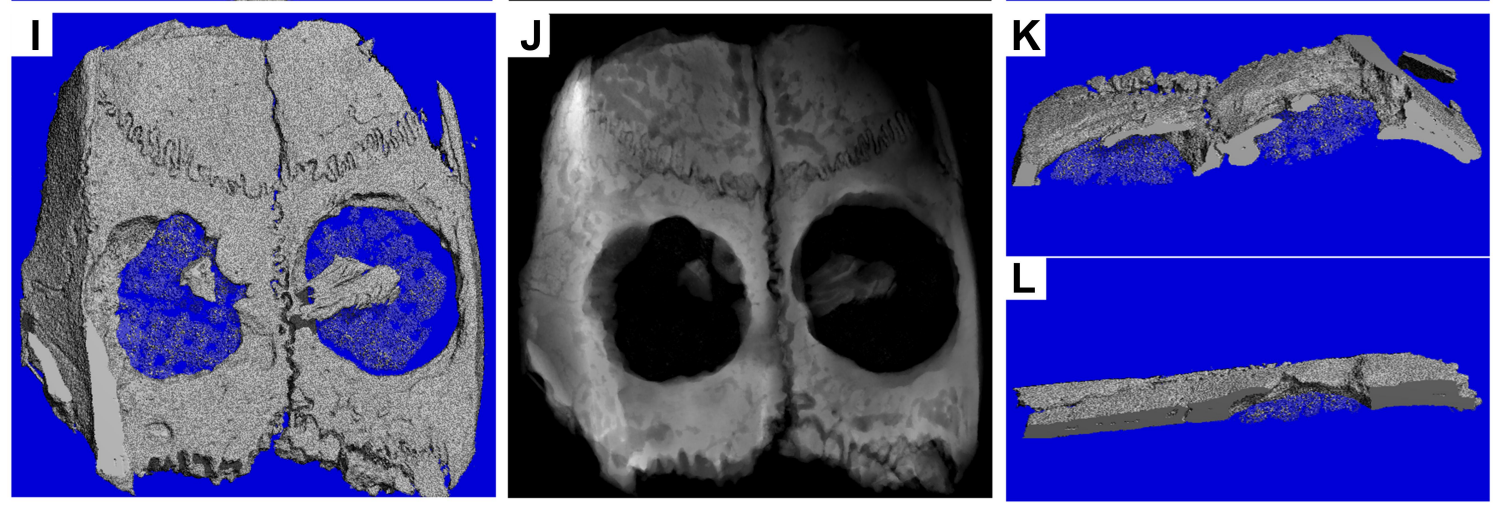

Coronal

s-ATP

Sagittal

Coronal

3D-ATP

Sagittal

Figure 9 Micro-CT images of the bone defects in rats after implantation of ATP scaffolds for eight weeks.(A-D) Blank group, (E-H) squashed ATP scaffold group and (I-L) 3D-ATP scaffold group. MIP is short for maximum intensity projection. Surface refers to outside appearance of cranium. Coronal plane is vertical to sagittal suture of rat's cranium. Sagittal plane is parallel to sagittal suture of rat's cranium. 
groups (Figures 8 and 9) and at four weeks postimplantation, the difference in new bone formation between s-ATP and blank groups was not significant (Figure $10 \mathrm{~A}-\mathrm{C})$. Maximum intensity projection of each group was used (Figures 8 and 9) for the evaluating extent of bony bridging. Figure 10 showed the results of this scoring for groups at four and eight weeks (Figure 10D-F). At four weeks, the 3D-ATP group was also significantly higher than the blank group (Figure 10E) while slight difference was observed between the 3DATP and s-ATP groups. 3D-ATP groups showed significantly higher scores for union compared with s-ATP and blank groups at eight weeks (Figure 10E). However, no significant difference of micro-CT score was observed between four and eight weeks in all groups respectively (Figure 10F).

\section{Histology Analysis}

Gross examination of the sections was performed for all samples. For all conditions with a scaffold implant, the scaffold material exhibits varying degrees of dissolution. Scaffold fragmentation was visible both at four and eight weeks. At four weeks, a thin fibrous capsule was observed as at interfaces between scaffolds and host bone (Figure 11B, C, $\mathrm{E}$ and F). A majority of the samples showed infiltration of immature fibrous tissue within the scaffold in (Figure 11B, C, E, F, H and I). There was little new bone formation in the blank group at four and eight weeks in Figures 11A and 12A. The 3D-ATP group (Figures 11 and 12) showed visibly higher amounts of bone formation near the interface within the scaffold compared with the s-ATP group at four and eight weeks. Interestingly, the new bone was formed along the defect margin, even above and within inner surface of ATP scaffolds (Figure 13). Intramembranous ossification was apparent within scaffolds and characterized by osteoid secretion and mineralization (Figure 13). In these cases, the new bone was often in close or direct contact with the scaffold, without presence of an intermediate fibrous layer. But the inflammatory response was minimal, with only a few inflammatory cells (neutrophils, macrophages) present at the interface between material and tissue and within the scaffolds (Figures 11 and 13). In addition, at eight weeks postimplantation, the 3D-ATP group (Figure 14) showed a notable amount of new vessel formation compared to that at four weeks.
A

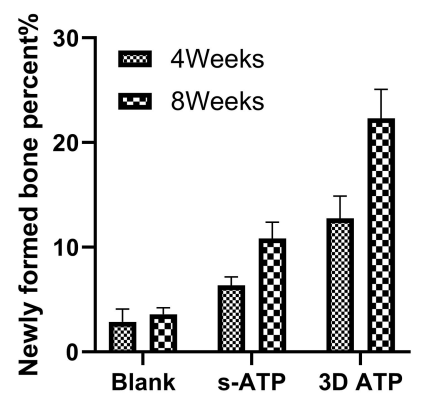

D

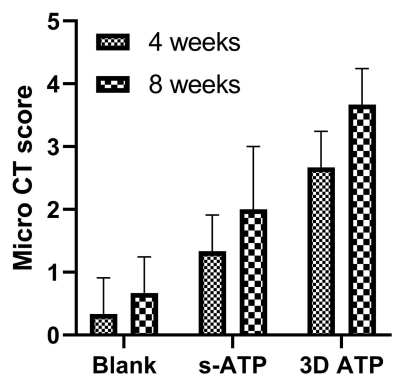

B

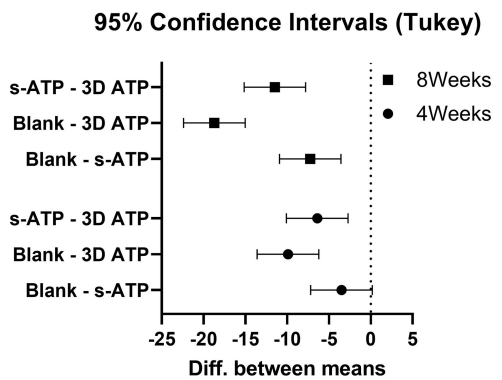

E

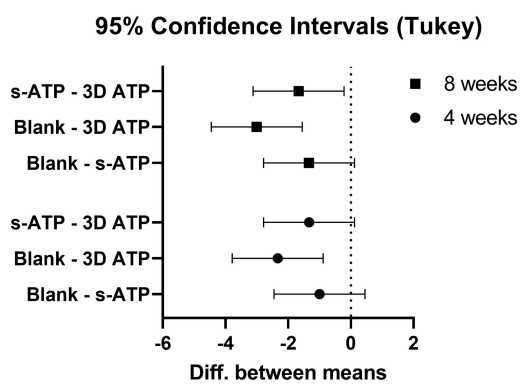

C

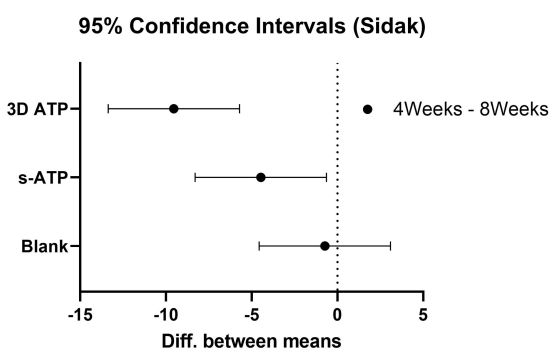

$\mathbf{F}$

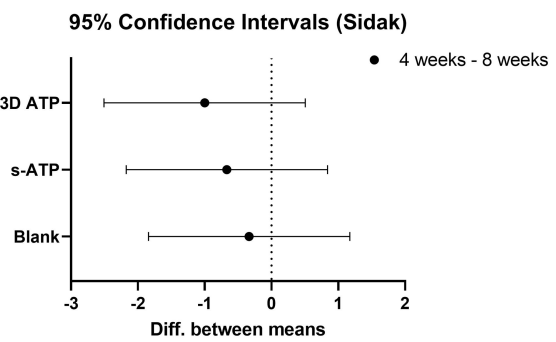

Figure 10 (A) Micro-CT quantitative analysis of new bone formation among various groups at 4 and 8 weeks; (D) Micro CT score for the evaluating extent of bony bridging among groups at 4 and 8 weeks along with, (B and E) multicomparisons following two-way analysis of variance (ANOVA) using a post hoc Tukey method as recommended to test differences between various groups at the given time points for newly formed bone percent and micro CT score respectively. (C and $\mathbf{F}$ ) multicomparisons following two-way analysis of variance (ANOVA) using a post hoc Sidak method as recommended to test differences between various time points within the given group for newly formed bone percent and micro CT score respectively. The $95 \% \mathrm{Cl}$ reveals that the result is statistically significant when " 0 " is not included in the interval, and vice versa. 


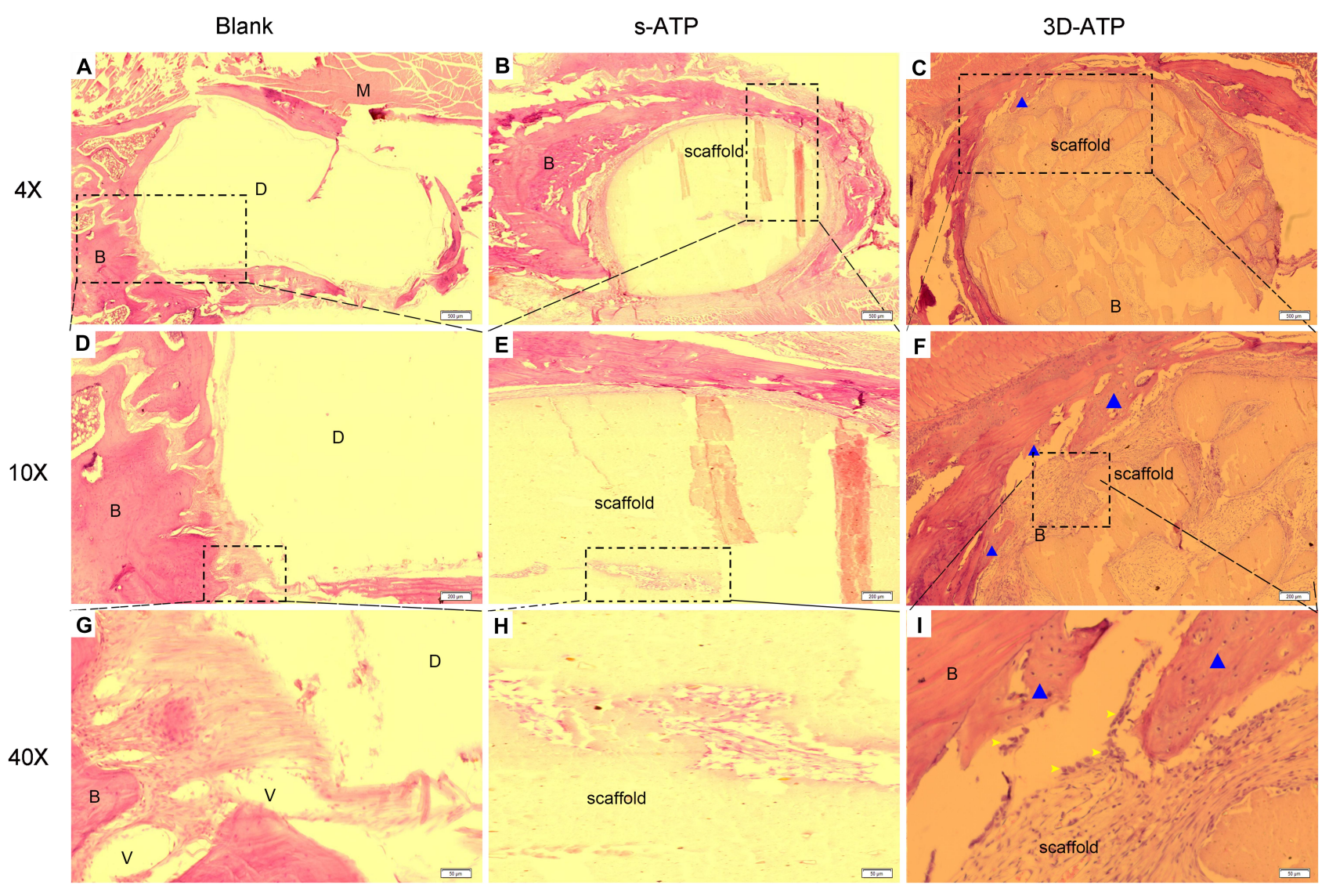

Figure II Histology evaluation of blank, s-ATP scaffold and 3D-ATP scaffold groups under magnifications of (A-C) 4x, (D-F) I0x and 40x (G-I) using H\&E staining examined at four weeks. ("B" for host bone, "M" for muscle, "D" for bone defect zone, "V" for blood vessel, blue triangle for newly formed bone, yellow arrow for osteoblasts) (blank represents the group that served as negative control and did not receive any therapy, s-ATP for the group of squashed ATP scaffolds, 3D-ATP for the group of 3D-printed scaffold).

\section{Discussion}

In our current study, we successfully designed a novel 3D nano-ATP scaffold and demonstrated the possibility of using the $3 \mathrm{D}$ bioprinting process chain to build porous scaffolds for bone tissue engineering. The bioactivity of osteogenesis was measured in vitro and in vivo. Firstly, nano-ATP scaffolds possess excellent biocompatibility for osteogenic cell of hBMSCs; secondly, the nano-ATP scaffolds could upregulate the expression of osteogenesis related genes and calcium deposits in vitro; thirdly, the $3 \mathrm{D}$ bioprinted porous ATP scaffolds demonstrated good performance of bone regeneration in a rat cranium defect model. These results suggest that the novel 3D bioprinted nano-ATP scaffolds are promising candidates for bone tissue engineering.

For bone tissue engineering, interconnecting channels and porosity of the scaffolds are very important. New fabrication techniques, such as 3D bioprinting, can potentially be used to generate scaffolds with morphological and mechanical properties more selectively designed to meet the specificity of bone repair needs. The porous trabeculae provide a high surface area which allows for nutrient diffusion and exposure to circulating growth factors. This access allows cancellous bone tissue to be metabolically active and can be remodeled more frequently than that of cortical bone. ${ }^{13}$ Based on Hulbert's study, the minimum pore size is considered to be $100 \mu \mathrm{m}$ due to cell size, migration requirements and transport. ${ }^{45}$ However, pore sizes $>300 \mu \mathrm{m}$ are recommended, due to enhanced new bone formation and the formation of capillaries. ${ }^{45}$ Results of Gauthier et al demonstrated a mean pore diameter of $565 \mu \mathrm{m}$ of inner channels in a scaffold showed more abundant newly formed bone both in peripheral and deep pores than those with $300 \mu \mathrm{m}$ pore size. ${ }^{46}$ Good osteointegration was seen in our 3D-printed nano-ATP scaffold with internal channels about $500 \mu \mathrm{m}$, and thus is close to the mentioned optimum channel size. Small pores favored hypoxic conditions and induced osteochondral formation before osteogenesis, while large pores, that are wellvascularized, lead to direct osteogenesis. This is consistent with our findings that new bone is directly formed within 


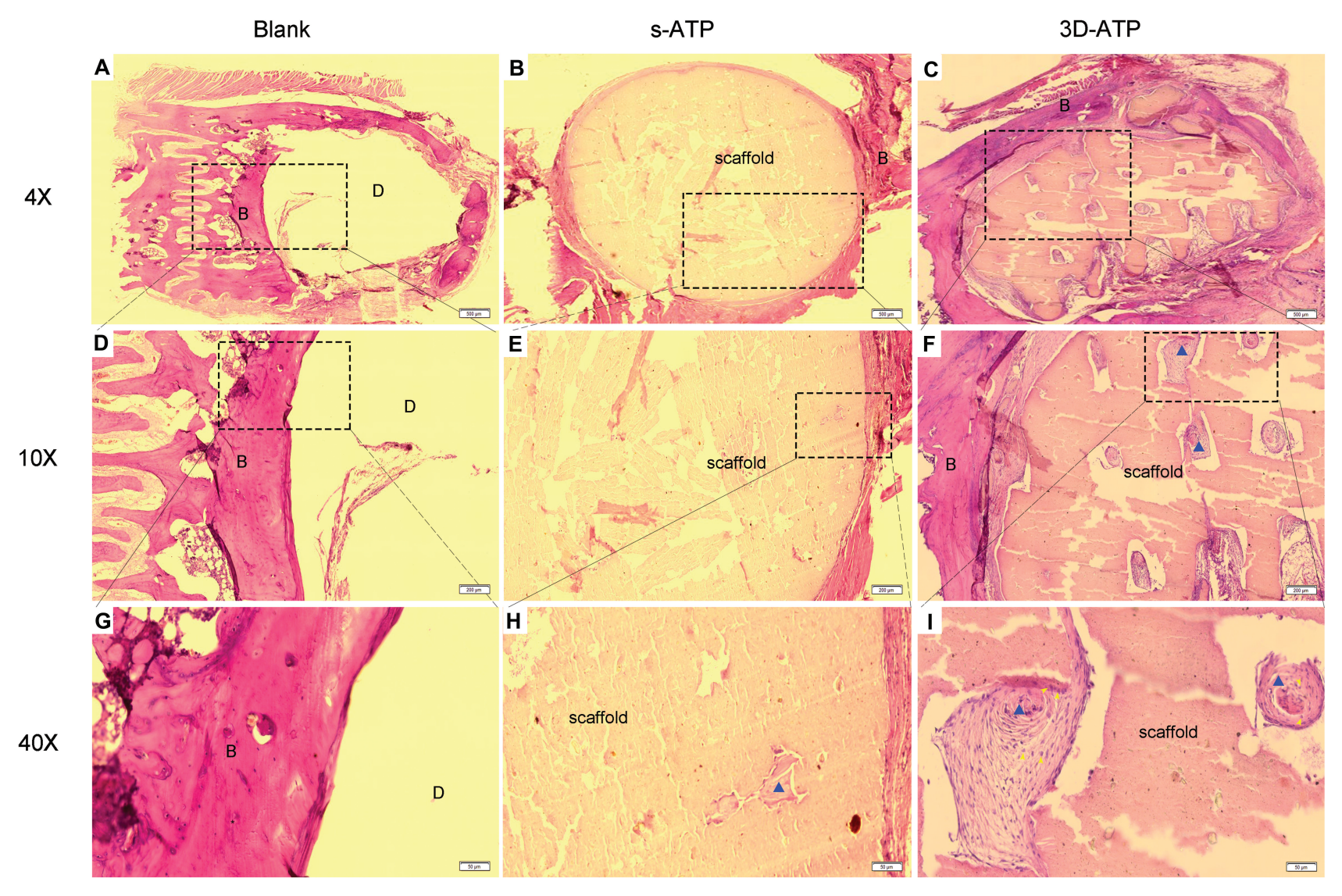

Figure 12 Histology evaluation of blank (A, D and $\mathbf{G})$, s-ATP scaffold (B, E and $\mathbf{H}$ ) and 3D-ATP scaffold (C, F and I) groups under different magnifications using $H \& E$ staining examined at eight weeks. ("B" for host bone, "D" for bone defect zone, blue triangle for newly formed bone, yellow arrow for osteoblasts) (blank represents the group that served as negative control and did not receive any therapy, s-ATP for the group of squashed ATP scaffolds, 3D-ATP for the group of 3D-printed scaffold).

pores and interface between host bone and scaffolds. In addition, the achieved wall thickness of the grid $(330 \mu \mathrm{m})$ is close to exactly mimic natural trabeculae of cancellous bone $(75-200 \mu \mathrm{m})$. Furthermore, our novel scaffolds are highly porous because of $10 \mathrm{wt} \%$ PVA (as a binder) assisted preparation of the green scaffolds. After sintering, the microporosity was formed and the macroporosity within scaffold was still preserved. The micro- and macroporosity of the scaffolds is supposed to enhance bone ingrowth as well as to improve the biodegradability of the fabricated scaffolds. ${ }^{47}$ Previous study found large amounts of new bone in a 3D-printed scaffold that contained pores less than $20 \mu \mathrm{m}$ in size. ${ }^{48}$ The pore size of the scaffolds in the present study was in the range of 20-50 $\mu \mathrm{m}$. However, newly formed bone was also seen within these micropores. The above findings suggest that the scaffolds of the present study offer a promising environment for cell adhesion and cell proliferation.

Higher porosity and pore size result in greater bone ingrowth. However, this trend results in compromised mechanical properties. Thus, a balance must be kept between osteconductibility and biomechanical property of the scaffold. The porosity of current 3D-printed scaffolds ranges from $75-82 \%$ and the longitudinal compression strength was measured to $4.32 \pm 0.52 \mathrm{MPa}$, which is similar to mechanical properties of cancellous bone (porosity 75-90\%; compressive strength $2-5 \mathrm{MPa}$ ). ${ }^{13}$

Bone is a nanomaterial composed of organic and inorganic components, with a hierarchical structure ranging from nanoscale to macroscale. Nanomaterials provide some new strategy in bone regeneration. Nanostructured scaffolds provide a closer structural support approximation to native bone architecture for the cells and regulate cell proliferation, differentiation, and migration, which results in the formation of functional tissues. ${ }^{7,49,50}$ Attapulgite is a naturally occurring clay material, a kind of magnesium aluminium phyllosilicate with formula $\left(\mathrm{Al}_{2} \mathrm{Mg}_{2}\right) \mathrm{Si}_{8} \mathrm{O}_{2}$ $0(\mathrm{OH})_{2}\left(\mathrm{OH}_{2}\right)_{4} \cdot 4 \mathrm{H}_{2} \mathrm{O}$. ATP has special rod crystal structure, which may therefore act directly as focal adhesion sites through the provision of reactive functional groups for cell 

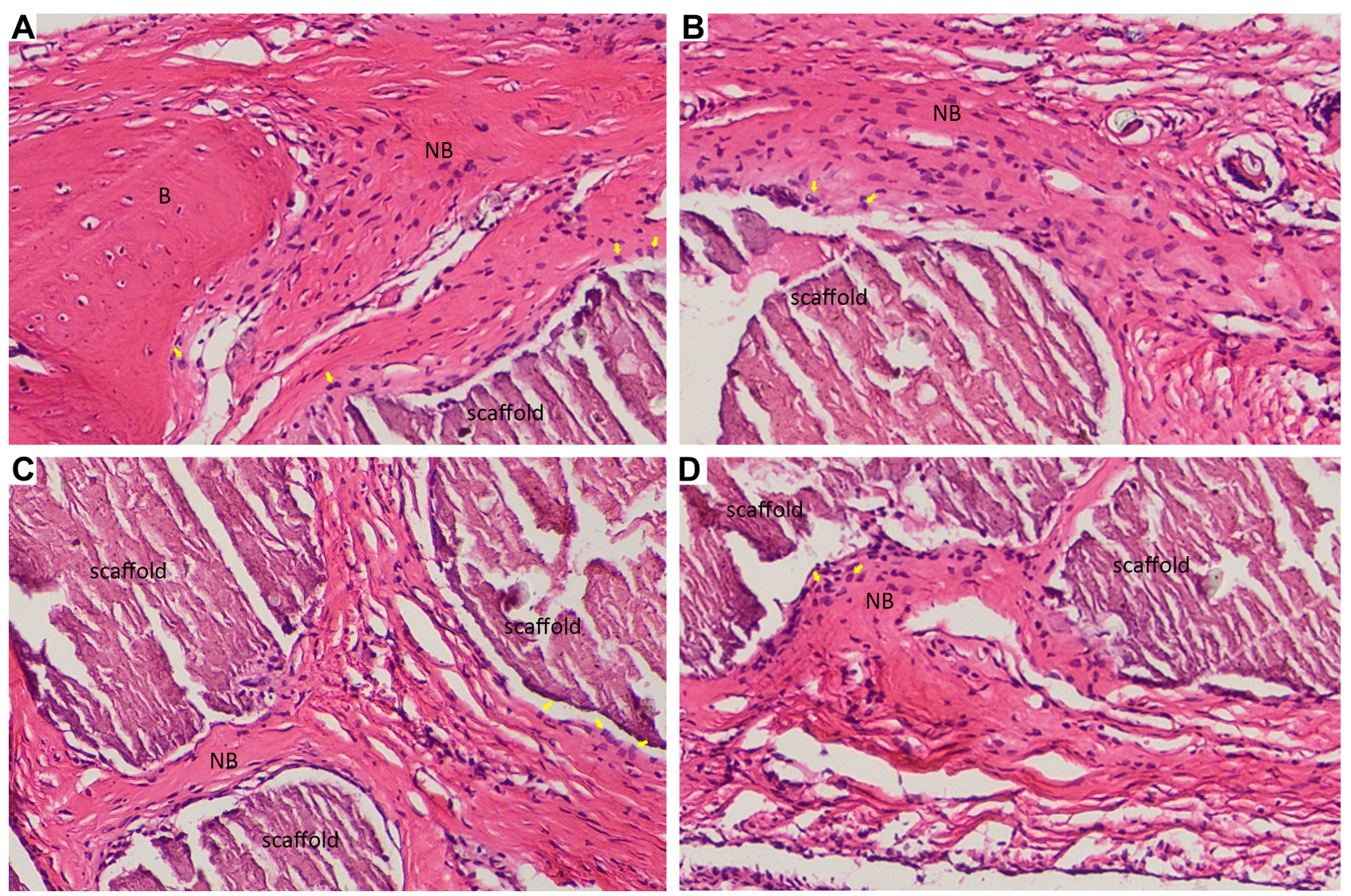

Figure 13 Histology evaluation of interface of 3D-ATP scaffolds using H\&E staining examined at eight weeks. ("B" for host bone, "NB" for newly formed bone, yellow arrow for osteoblasts.) (A) Interface between host bone and scaffold, (B) superior surface of 3D-ATP scaffolds, (C) within scaffold, (D) inferior surface of 3D-ATP scaffolds.
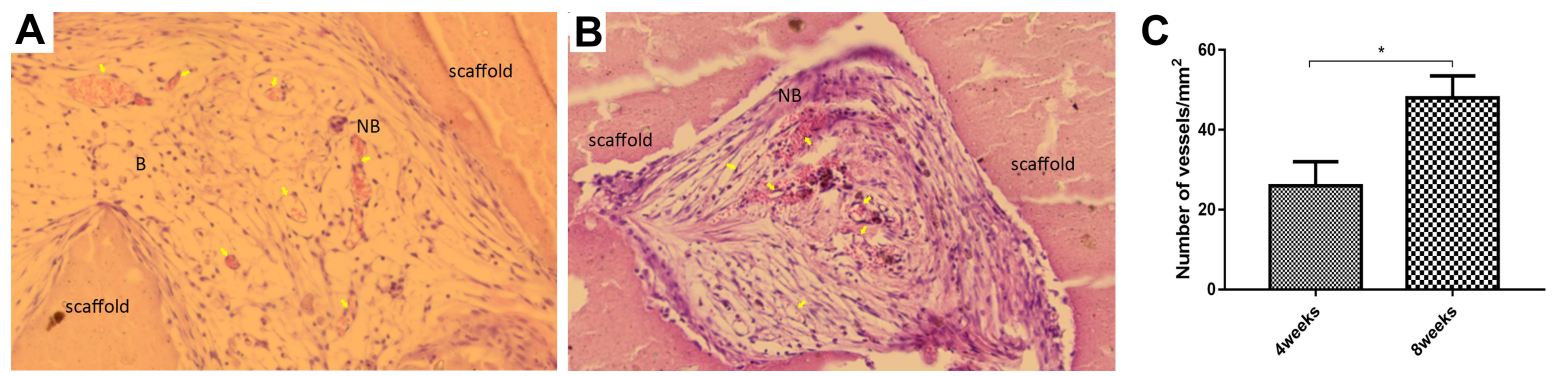

4weeks

\$ 8 weeks

Figure 14 Neovessel density analysis within 3D-ATP scaffolds at four and eight weeks. ("B" for host bone, "NB" for newly formed bone, yellow arrow for newly formed vessels.) (A) Four weeks after surgery, (B) eight weeks after surgery, (C) statistical analysis. $* P<0.05$.

attachment. ${ }^{17}$ Another possible mechanism could be increased local concentrations of divalent cations such as $\mathrm{Ca}^{2+}$ or $\mathrm{Mg}^{2+}$ which exchange on ATP particle surfaces preferentially over monovalent ions given their increased charge density. Such divalent ions are essential for the function of integrins, the transmembrane receptors that mediate cell interactions with ECM. ${ }^{51}$ The mechanism underlying that ATP promote osteogenic differentiation of osteogenic precursor cell remain poorly understood. The known osteogenic effects of ATP are partially ascribed to
$\mathrm{Mg}^{2+}$ the upregulated expression of calcitonin gene-related peptide (CGRP) in the periosteum. ${ }^{52}$ The increase of CGRP level could enhance osteogenic differentiation of precursor cell such as MSC. ${ }^{52}$ Furthermore, angiogenesis is a key component of bone repair. New blood vessels bring oxygen and nutrients to the highly metabolically active regenerating callus and serve as a route for inflammatory cells and cartilage and bone precursor cells to reach the injury site. ${ }^{53}$ Magnesium ions are involved in activating HIF-1a signaling pathway, which is primary signal that directly 
increases VEGF gene expression. ${ }^{17}$ As seen obviously in our nano-ATP scaffolds at the fourth and eighth weeks, there were a plenty of neovessels within the pores. This is in agreement with the aforementioned potential mechanism.

The highlights of our study include its comprehensive design combing in vitro and in vivo experiments. Several limitations must be considered in the present study. Firstly, the possible further mechanisms under osteogenic effect of ATP were not explored in vitro such as immunohistochemical staining. Secondly, a well-accepted positive control group such as nanohydroxyapatite should be considered for more exactly evaluating the bone regeneration of the 3D-printed nano-ATP scaffolds. Thirdly, evaluation of angiogenesis in vivo (such as microfil perfusion) in the present study is not mentioned for comprehensively assessing repair effect of the scaffolds.

\section{Conclusion}

For the first time, our current findings demonstrate that nano-ATP powder assisted with PVA is able to achieve a remarkable printability for 3D-printed scaffold fabrication, and the novel 3D-printed nano-ATP scaffolds possess excellent mechanical property and compatibility. 3Dprinted nano-ATP scaffolds could directly induce bone formation by membranous ossification and promote revascularization of defect zone. Above all, 3D-printed porous nano-ATP scaffolds are promising candidates for bone tissue engineering by osteogenesis and angiogenesis.

\section{Acknowledgments}

The authors are grateful for financial support of the Major Projects of the Natural Science Foundation of Gansu, China (18JR4RA001) and the Funds for Creative Research Groups of Gansu, China (17JR5RA306). We are grateful for the help provided from Prof. Zilin Qiao and School of Life Science and Engineering, Northwest University, Lanzhou, China.

\section{Disclosure}

Xiaohan Ye is an employee of Beijing Tiantan Biological Products Co., Ltd. The authors report no other potential conflicts of interest in this work.

\section{References}

1. Lomas R, Chandrasekar A, Board TN. Bone allograft in the U.K.: perceptions and realities. Hip Int. 2013;23(5):427-433. doi:10.5301/ hipint. 5000018

2. Mankin HJ, Hornicek FJ, Raskin KA. Infection in massive bone allografts. Clin Orthop Relat Res. 2005;\&NA;(432):210-216. doi:10.1097/01.blo.0000150371.77314.52
3. Hollister SJ. Porous scaffold design for tissue engineering. Nat Mater. 2005;4(7):518-524. doi:10.1038/nmat1421

4. Jiang L, Li Y, Xiong C, Su S, Ding H. Preparation and properties of bamboo fiber/nano-hydroxyapatite/poly(lactic-co-glycolic) composite scaffold for bone tissue engineering. ACS Appl Mater Interfaces. 2017;9(5):4890-4897. doi:10.1021/acsami.6b15032

5. Burg KJ, Porter S, Kellam JF. Biomaterial developments for bone tissue engineering. Biomaterials. 2000;21(23):2347-2359. doi:10.10 16/S0142-9612(00)00102-2

6. Wu S, Li Y. Editorial for rare metals, special issue on biomedical metal implants. Rare Metals. 2019;38(6):475. doi:10.1007/s12598-019-01254-x

7. Ma J, Zan R, Chen W, Ni J, Zhang X. Cell behaviors on surface of pure tantalum with nano-dimpled structure. Rare Metals. 2019;38 (6):543-551. doi:10.1007/s12598-019-01226-1

8. Li B-Q, Li C-L, Wang Z-X, Lu X. Preparation of Ti-Nb-Ta-Zr alloys for load-bearing biomedical applications. Rare Metals. 2019;38(6):571-576. doi:10.1007/s12598-019-01239-w

9. Guo Y, Guan J, Yang J, Wang Y, Zhang C, Ke Q. Hybrid nanostructured hydroxyapatite-chitosan composite scaffold: bioinspired fabrication, mechanical properties and biological properties. J Mater Chem B. 2015;3:4679-4689. doi:10.1039/C5TB00175G

10. Thomas MV, Puleo DA. Calcium sulfate: properties and clinical applications. J Biomed Mater Res B Appl Biomater. 2009;88B (2):597-610. doi:10.1002/jbm.b.31269

11. Huang Y, Wu C, Zhang X, Chang J, Dai K. Regulation of immune response by bioactive ions released from silicate bioceramics for bone regeneration. Acta Biomater. 2018;66:81-92. doi:10.1016/j.actbio.2017.08.044

12. Wu C, Chang J. A review of bioactive silicate ceramics. Biomed Mater. 2013;8(3):032001. doi:10.1088/1748-6041/8/3/032001

13. Polo-Corrales L, Latorre-Esteves M, Ramirez-Vick JE. Scaffold design for bone regeneration. J Nanosci Nanotechnol. 2014;14 (1):15-56. doi:10.1166/jnn.2014.9127

14. Sandri G, Bonferoni MC, Rossi S, et al. Clay minerals for tissue regeneration, repair, and engineering. In: Ågren MS, editor. Wound Healing Biomaterials. Woodhead Publishing; 2016:385-402.

15. Vergaro V, Abdullayev E, Lvov YM, et al. Cytocompatibility and uptake of halloysite clay nanotubes. Biomacromolecules. 2010;11 (3):820-826. doi:10.1021/bm9014446

16. Dawson JI, Oreffo RO. Clay: new opportunities for tissue regeneration and biomaterial design. Adv Mater. 2013;25(30):4069-4086. doi:10.1002/adma.201301034

17. Mousa M, Evans ND, Oreffo ROC, Dawson JI. Clay nanoparticles for regenerative medicine and biomaterial design: A review of clay bioactivity. Biomaterials. 2018;159:204-214. doi:10.1016/ j.biomaterials.2017.12.024

18. Stevens MM, Khademhosseini A. Emerging materials for tissue engineering and regenerative medicine: themed issue for soft matter and journal of materials chemistry. Soft Matter. 2010;6:4962. doi:10.1039/c0sm90029j

19. Ali A, Ahmed S. A review on chitosan and its nanocomposites in drug delivery. Int J Biol Macromol. 2018;109:273-286. doi:10.1016/ j.ijbiomac.2017.12.078

20. Norouz F, Halabian R, Salimi A, Ghollasi M. A new nanocomposite scaffold based on polyurethane and clay nanoplates for osteogenic differentiation of human mesenchymal stem cells in vitro. Mater Sci Eng C Mater Biol Appl. 2019;103:109857. doi:10.1016/j.msec.2019.109857

21. Baker SE, Sawvel AM, Zheng N, Stucky GD. Controlling bioprocesses with inorganic surfaces: layered clay hemostatic agents. Chem Mater. 2007;19(18):4390-4392. doi:10.1021/cm071457b

22. Gaharwar AK, Schexnailder P, Kaul V, et al. Highly extensible bio-nanocomposite films with direction-dependent properties. $A d v$ Funct Mater. 2010;20(3):429-436. doi:10.1002/adfm.200901606

23. Tao L, Zhonglong L, Ming X, et al. In vitro and in vivo studies of a gelatin/carboxymethyl chitosan/LAPONITE ${ }^{\circledR}$ composite scaffold for bone tissue engineering. RSC $A d v$. 2017;7:54100-54110. doi:10. 1039/C7RA06913H 
24. Schexnailder PJ, Gaharwar AK, Bartlett RL, Seal BL, Schmidt G. Tuning cell adhesion by incorporation of charged silicate nanoparticles as cross-linkers to polyethylene oxide. Macromol Biosci. 2010;10(12):1416-1423. doi:10.1002/mabi.201000053

25. Wang W, Wang A. Recent progress in dispersion of palygorskite crystal bundles for nanocomposites. Appl Clay Sci. 2016;119(Pt 1):18-30. doi:10.1016/j.clay.2015.06.030

26. Drits VA, Sokolova GV. Structure of palygorskite. Sov Phys Crystallogr. 1971;16:183-185.

27. Dong W, Lu Y, Wang W, Zhang M, Jing Y, Wang A. A sustainable approach to fabricate new $1 \mathrm{D}$ and $2 \mathrm{D}$ nanomaterials from natural abundant palygorskite clay for antibacterial and adsorption. Chem Eng J. 2020;382:122984. doi:10.1016/j.cej.2019.122984

28. Wang H, Wang X, Ma J, Xia P, Zhao J. Removal of cadmium (II) from aqueous solution: A comparative study of raw attapulgite clay and a reusable waste-struvite/attapulgite obtained from nutrient-rich wastewater. $J$ Hazard Mater. 2017;329:66-76. doi:10.1016/j.jhazmat.2017.01.025

29. Xiang C, Zhang J, Yu O, Dong M, Tan S, Peng Y. Bacteria-adsorbed palygorskite stabilizes the quaternary phosphonium salt with specific-targeting capability, long-term antibacterial activity, and lower cytotoxicity. Langmuir. 2013;29(17):5279-5285.

30. Ezzatahmadi N, Millar GJ, Ayoko GA, et al. Degradation of 2,4-dichlorophenol using palygorskite-supported bimetallic $\mathrm{Fe} / \mathrm{Ni}$ nanocomposite as a heterogeneous catalyst. Appl Clay Sci. 2019;168:276-286. doi:10.1016/j.clay.2018.11.030

31. Cai D, Zhang H, Tang Y, Chu PK, Yu Z, Wu Z. Nano-networks have better adsorption capability than nano-rods. Nano Commun Netw. 2010;1(4):257-263. doi:10.1016/j.nancom.2010.12.001

32. Wang W, Wang F, Kang Y, Wang A. Nanoscale dispersion crystal bundles of palygorskite by associated modification with phytic acid and high-pressure homogenization for enhanced colloidal properties. Powder Technol. 2015;269:85-92. doi:10.1016/j.powtec.2014.09.015

33. Xu J, Wang W, Wang A. Stable formamide/palygorskite nanostructure hybrid material fortified by high-pressure homogenization. Powder Technol. 2017;318:1-7. doi:10.1016/j.powtec.2017.05.032

34. Liu X, Xu X, Sun J, et al. Insight into the impact of interaction between attapulgite and graphene oxide on the adsorption of $\mathrm{U}(\mathrm{VI})$. Chem Eng J. 2018;343:217-224. doi:10.1016/j.cej.2018.02.113

35. Matai I, Kaur G, Seyedsalehi A, McClinton A, Laurencin CT. Progress in 3D bioprinting technology for tissue/organ regenerative engineering. Biomaterials. 2020;226:119536. doi:10.1016/j. biomaterials.2019.119536

36. Wang Y, Gao M, Wang D, Sun L, Webster TJ. Nanoscale 3D bioprinting for osseous tissue manufacturing. Int $J$ Nanomedicine. 2020;15:215-226. doi:10.2147/IJN.S172916

37. Zhu Y, Liu K, Deng J, et al. 3D printed zirconia ceramic hip joint with precise structure and broad-spectrum antibacterial properties. Int J Nanomedicine. 2019;14:5977-5987. doi:10.2147/IJN.S202457

38. Qasim M, Chae DS, Lee NY. Advancements and frontiers in nano-based 3D and 4D scaffolds for bone and cartilage tissue engineering. Int J Nanomedicine. 2019;14:4333-4351. doi:10.2147/IJN.S209431

39. Zhang Y, Yu W, Ba Z, Cui S, Wei J, Li H. 3D-printed scaffolds of mesoporous bioglass/gliadin/polycaprolactone ternary composite for enhancement of compressive strength, degradability, cell responses and new bone tissue ingrowth. Int $J$ Nanomedicine. 2018;13: 433-5447. doi:10.2147/IJN.S164869

International Journal of Nanomedicine

\section{Publish your work in this journal}

The International Journal of Nanomedicine is an international, peerreviewed journal focusing on the application of nanotechnology in diagnostics, therapeutics, and drug delivery systems throughout the biomedical field. This journal is indexed on PubMed Central, MedLine, CAS, SciSearch ${ }^{\mathbb{R}}$, Current Contents ${ }^{\mathbb{R}} /$ Clinical Medicine, $^{2}$
40. Keller L, Idoux-Gillet Y, Wagner Q, et al. Nanoengineered implant as a new platform for regenerative nanomedicine using $3 \mathrm{D}$ well-organized human cell spheroids. Int J Nanomedicine. 2017;12:447-457. doi:10. 2147/IJN.S116749

41. Shahini A, Yazdimamaghani M, Walker KJ, et al. 3D conductive nanocomposite scaffold for bone tissue engineering. Int J Nanomedicine. 2014;9:167-181. doi:10.2147/IJN.S54668

42. Xu J, Wang W, Wang A. Enhanced microscopic structure and properties of palygorskite by associated extrusion and high-pressure homogenization process. Appl Clay Sci. 2014;95:365-370. doi:10.1016/j. clay.2014.02.011

43. Chaudhuri B, Mondal B, Ray SK, Sarkar SC. A novel biocompatible conducting polyvinyl alcohol (PVA)-polyvinylpyrrolidone (PVP)-hydroxyapatite (HAP) composite scaffolds for probable biological application. Colloids Surf B Biointerfaces. 2016;43:71-80. doi:10.1016/j.colsurfb.2016.03.027

44. Patel ZS, Young S, Tabata Y, Jansen JA, Wong ME, Mikos AG. Dual delivery of an angiogenic and an osteogenic growth factor for bone regeneration in a critical size defect model. Bone. 2008;43 (5):931-940. doi:10.1016/j.bone.2008.06.019

45. Karageorgiou V, Kaplan D. Porosity of 3D biomaterial scaffolds and osteogenesis. Biomaterials. 2005;26(27):5474-5491. doi:10.1016/j. biomaterials.2005.02.002

46. Gauthier O, Bouler JM, Aguado E, Pilet P, Daculsi G. Macroporous biphasic calcium phosphate ceramics: influence of macropore diameter and macroporosity percentage on bone ingrowth. Biomaterials. 1998;19(1-3):133-139. doi:10.1016/S0142-9612(97)00180-4

47. Weiss P, Obadia L, Magne D, et al. Synchrotron X-ray microtomography (on a micron scale) provides three-dimensional imaging representation of bone ingrowth in calcium phosphate biomaterials. Biomaterials. 2003;24 (25):4591-4601. doi:10.1016/S0142-9612(03)00335-1

48. Dutta Roy T, Simon JL, Ricci JL, Rekow ED, Thompson VP, Parsons JR. Performance of hydroxyapatite bone repair scaffolds created via three-dimensional fabrication techniques. J Biomed Mater Res A. 2003;67A(4):1228-1237. doi:10.1002/jbm.a.20034

49. Gong T, Xie J, Liao J, Zhang T, Lin S, Lin Y. Nanomaterials and bone regeneration. Bone Res. 2015;3(1):1-7. doi:10.1038/boneres. 2015.29

50. Fu J, Liu X, Tan L, et al. Modulation of the mechanosensing of mesenchymal stem cells by laser-induced patterning for the acceleration of tissue reconstruction through the $\mathrm{Wnt} / \beta$-catenin signaling pathway activation. Acta Biomater. 2020;101:152-167. doi:10.1016/ j.actbio.2019.10.041

51. Hynes RO. Integrins: bidirectional, allosteric signaling machines. Cell. 2002;110(6):673-687. doi:10.1016/S0092-8674(02)00971-6

52. Zhao D, Witte F, Lu F, Wang J, Li J, Qin L. Current status on clinical applications of magnesium-based orthopaedic implants: A review from clinical translational perspective. Biomaterials. 2017;112: 287-302. doi:10.1016/j.biomaterials.2016.10.017

53. Hankenson KD, Dishowitz M, Gray C, Schenker M. Angiogenesis in bone regeneration. Injury. 2011;42(6):556-561. doi:10.1016/j.injury. 2011.03.035

Journal Citation Reports/Science Edition, EMBase, Scopus and the Elsevier Bibliographic databases. The manuscript management system is completely online and includes a very quick and fair peer-review system, which is all easy to use. Visit http://www.dovepress.com/ testimonials.php to read real quotes from published authors. 